ESTEVAM RUBENS UTUMI

\title{
AVALIAÇÃO DE LESÕES ÓSSEAS SIMULADAS NA CABEÇA DA MANDÍBULA PELA TOMOGRAFIA COMPUTADORIZADA MULTISLICE
}




\section{Estevam Rubens Utumi}

\section{Avaliação de lesões ósseas simuladas na cabeça da mandíbula pela tomografia computadorizada multislice}

Tese apresentada à Faculdade de Odontologia da Universidade de São Paulo, para obter o título de Mestre pelo Programa de Pós-Graduação em Ciências Odontológicas.

Área de concentração: Clínica Integrada

Orientador: Prof. Dr. Marcelo Gusmão Paraíso Cavalcanti 


\section{FOLHA DE APROVAÇÃO}

Utumi ER. Avaliação de lesões ósseas simuladas na cabeça da mandíbula pela tomografia computadorizada multislice [Dissertação de Mestrado]. São Paulo: Faculdade de Odontologia da USP; 2008.

São Paulo:

Banca Examinadora

1) $\operatorname{Prof}(a) \cdot \operatorname{Dr}(a)$ :

Titulação:

Julgamento:

Assinatura:

2) Prof(a).Dr(a):

Titulação:

Julgamento:

Assinatura:

3) $\operatorname{Prof}(a) \cdot \operatorname{Dr}(a)$ :

Titulação:

Julgamento:

Assinatura: 


\section{DEDICATÓRIA}

Este trabalho é inteiramente dedicado a duas pessoas essenciais na minha vida, pessoas nas quais me espelhei, e que me deram incentivo, apoio e suporte para todos os obstáculos da vida.

Aos meus pais tão amados e queridos: Noboru Utumi e Silvia Regina Utumi. 


\section{AGRADECIMENTOS ESPECIAIS}

À minha amada Evanir Gomes Bandeira, que com seu amor, paciência, tolerância e amizade me ensina a viver. Minha fonte inspiradora de meus pensamentos únicos.

Ao meu amigo Massaki Matsuno, pela amizade e convivência de mais de 20 anos, que essa amizade cresça ainda mais.

À minha amiga eterna Célia Sayuri Tsukasaki (In memorian) que me incentivou e despertou o interesse na odontologia. 


\section{AGRADECIMENTOS ESPECIAIS AO ORIENTADOR}

Ao Professor Livre Docente Dr. Marcelo de Gusmão Paraíso Cavalcanti

Agradeço-Ihe a confiança depositada em mim desde o início de minha carreira e de fazer parte do grupo.

Agradeço-Ihe a satisfação de ter tido um orientador exemplar que me incentivou não somente na pesquisa, mas na integridade profissional e pessoal.

Que eu ainda faça parte de seu grupo de vencedores. 


\section{AGRADECIMENTOS}

Ao diretor da Disciplina de Clínica Integrada professor Dr. Rodney Garcia Rocha, pelo apoio e incentivo de realizar minha pesquisa.

A todos os professores da Disciplina de Clínica Integrada da Faculdade de Odontologia da Universidade de São Paulo, pelos ensinamentos profissionais e pela convivência.

Às secretárias Vilma e Vera, da Disciplina de Clínica Integrada, pela colaboração, dedicação e carinho.

Aos meus colegas da pós: Alexandre, Anna, Endrigo, Irineu, Kazue, Leopoldo, Marcelo, Maurício, Mayara e Renata. Em especial aos amigos Endrigo e Irineu pela amizade, convivência e momentos de descontrações.

Aos amigos do Labi 3D e suas gerações: Adriana, Adriana Paula, Alexandre, Andréia, Ana Claudia, Bruno, Carla, Caio, Denise, Luciana, Marcelo Sales, Marco, Mariana, Nicole, Patrícia, Sara. Pela amizade, apoio e incentivo. Certamente é um grupo de vencedores.

Aos amigos assistentes e ex-residentes da Divisão de Odontologia do Hospital das Clínicas da FMUSP. Em especial ao Serviço de Cirurgia Traumatologia Buco-Maxilo-Facial: André Caroli, Camila Zambon, Cristiano Gaujac, Daniel Bernabé, Frederico Yonezaki, Jan Peter Ilg, Marcelo Ceccheti, Ney Penteado, Paulo de Tarso, Maria Paula S. M. Peres. Pela amizade, convivência e aprendizado. 
Paras as bibliotecárias: Vânia/Glauci/Aguida/Maria Aparecida não apenas pela correção da tese, mas pela presteza e gentileza.

Aos meus familiares que direta e indiretamente me deram apoio a minha tese.

À FAPESP, Fundação de Amparo à Pesquisa do Estado de São Paulo, pela bolsa auxílio mestrado. 
"Sucesso é conseguir aquilo que quer... felicidade é querer aquilo que conseguiu. Lute pelos seus sonhos..."

Anônimo 
Utumi ER. Avaliação de lesões ósseas simuladas na cabeça da mandíbula pela tomografia computadorizada multislice [Dissertação de Mestrado]. São Paulo: Faculdade de Odontologia da USP; 2008.

\section{RESUMO}

A região da articulação temporomandibular (ATM) possui uma limitação na obtenção de imagens pela radiografia convencional. A tomografia computadorizada é o exame mais indicado pela alta especificidade e sensibilidade, para o diagnóstico, planejamento cirúrgico e tratamento das lesões ósseas. O objetivo deste trabalho consiste na avaliação de lesões ósseas simuladas na cabeça da mandíbula pela tomografia computadorizada. Foram utilizadas 15 mandíbulas secas, onde foram criadas lesões esféricas, com o auxílio de brocas esféricas cirúrgicas de uso odontológico com tamanhos variados $\left(n^{\circ} 1,3,6\right)$ na cabeça da mandíbula. As lesões foram avaliadas por meio da TC multislice (64 canais), por 2 examinadores independentemente, em 02 ocasiões distintas, utilizando 2 protocolos: axial, coronal, sagital e imagens parassagitais para visualização dos pólos (anterior, lateral, posterior, medial, superior). Posteriormente, as imagens foram comparadas com as lesões presentes na mandíbula seca (Padrão Ouro) avaliando o grau de especificidade e sensibilidade da TC. Estatística de Kappa, teste de validade e teste do Qui-Quadrado foram utilizados como métodos estatísticos. Como resultados observaram a vantagem da associação dos cortes axial, coronal e sagital com cortes parassagitais para detecção de lesões na região de cabeça de mandíbula. Para determinada localização de lesões nos pólos, os tipos de protocolos não apresentaram diferenças significativas em relação as porcentagens de concordância. Os protocolos para visualização da região de cabeça da mandíbula 
foram estabelecidos no intuito de melhorar a visualização da presença de alterações de cada pólo da cabeça da mandíbula. No que se refere aos pólos avaliados pelos cortes parassagitais houve melhor visualização no pólo anterior e posterior no sentido látero medial. Nos pólos superior, medial e lateral foram mais bem visualizados no sentido ântero-posterior.

Palavras Chaves: tomografia; tomografia computadorizada por raios $\mathrm{X}$, doenças ósseas, côndilo 
Utumi ER Evaluation of simulated bone lesion in the head of the jaw by using multislice computed tomography [Dissertação de Mestrado]. São Paulo: Faculdade de Odontologia da USP; 2008.

\begin{abstract}
There are limitations for image acquisition using conventional radiography of the temporomandibular joint (ATM) region. Computerized tomography (CT) scan is a better option due to its higher specificity and sensitivity for diagnosis, surgical planning and treatment of bone injuries. The purpose of this study is to evaluate simulated bone injuries of the head of the jaw by CT scan. Spherical lesions were created in the head of 15 dry jaws with dentist drills (sizes 1, 3, and 6). Lesions were evaluated using the CT multislice (64 bits) by 2 examiners independently, in 2 different occasions, using 2 protocols: axial, coronal, and sagittal and parasagittal images for head of the mandible visualization (anterior, lateral, posterior, medial, and superior). Images were compared with the dry jaw (gold standard) regarding the presence of injuries, evaluating the degree of specificity and sensitivity of the CT. Kappa statistics, validity tests, and chi-square tests were used as statistical methods. As a result, we observed the advantage of the association of axial, coronal and sagittal slices with parasagittal slices for detection of lesions in the region of mandible's head. For some lesions localized in polar regions, protocols did not show statistically significant differences regarding the proportion of agreement. Protocols for visualization were created to improve the visualization of lesions in each polar region of the jaw's head. Regarding parassagittal slices, there was better lateromedial visualization of the anterior and posterior poles and better anteroposterior visualization of superior, medial, and lateral poles.
\end{abstract}

Keyword: tomography ; X-ray computed tomography, bone diseases, condyle 


\section{LISTA DE ILUSTRAÇÕES}

Figura 4.1 - Localização onde serão feitas as perfurações

34

Figura 4.2 - Perfurações localizadas em diferentes pólos 34

Figura 4.3 - Tomografia computadorizada espiral multislice 64 cortes/0,5 segundo (Aquilion, Toshiba Medical Systems, Tustin, CA, EUA).

Figura 4.4 - Posicionamento da mandíbula no interior do recipiente com água simulando o posicionamento do paciente no tomógrafo 36

Figura 4.5- Tela do programa de visualização de imagens do programa Radiostudio

Figura 4.6 - Imagem das demarcações parassagitais e visualização dos cortes reconstruídos 40

Figura 4.7 - Demarcações parassagitais no sentido látero-medial. 40

Figura 4.8 - Demarcações parassagitais no sentido ântero-posterior 41 


\section{LISTA DE TABELAS}

Tabela 5.1 - Tabela da análise das imagens axial, coronal, sagital: Kappa intra e inter observadores.

Tabela 5.2 - Tabela da análise das imagens parasagitais: Kappa intra e inter observadores

Tabela 5.3 - Tabela da análise das imagens axial, coronal, sagital: Kappa em relação ao padrão ouro

Tabela 5.4 - Tabela da análise das imagens parassagitais: Kappa em relação ao padrão ouro

Tabela 5.5 - Tabela do estudo da procentagem de concordância em cada pólo analisado.

Tabela 5.6 - Tabela do estudo do número de perfurações encontradas cada polo .46

Tabela 5.7 - Tabela do número de perfurações em relações às brocas e padrão ouro.

Tabela 5.8 - Tabela das procentagens de falsos negativos, segundo a broca para cada observador em cada pólo analisado.

Tabela 5.9 - Tabela dos valores de sensibilidade (\%)

Tabela 5.10 -Tabela dos valores de espeficidade (\%) 


\section{SUMÁRIO}

p.

1 INTRODUÇÃO

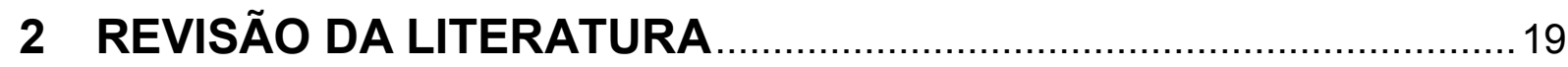

2.1 Tomografia Computadorizada Espiral .................................................. 19

2.2 Aplicações da Tomografia Computadorizada nas regiões da articulação

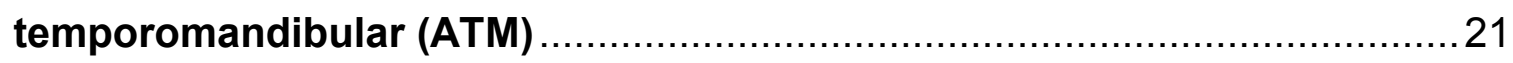

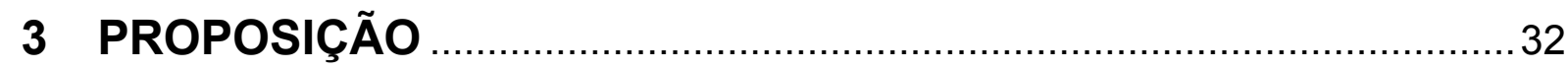

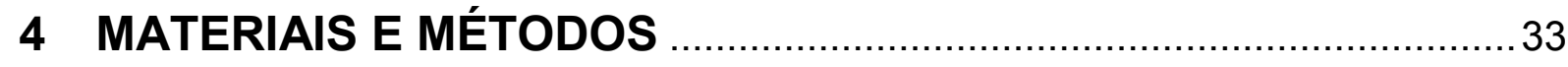

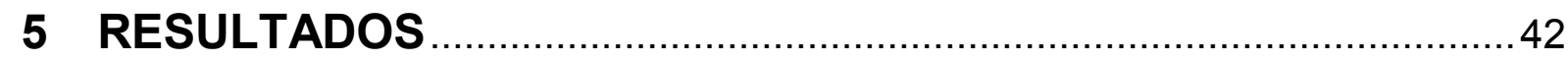

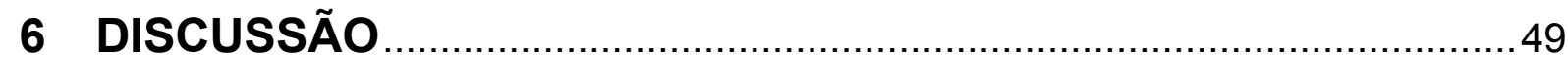

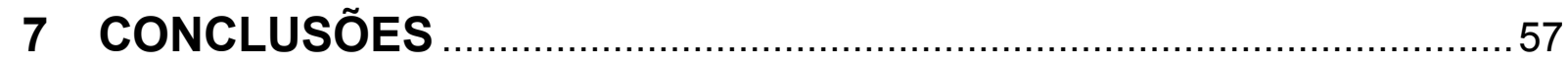

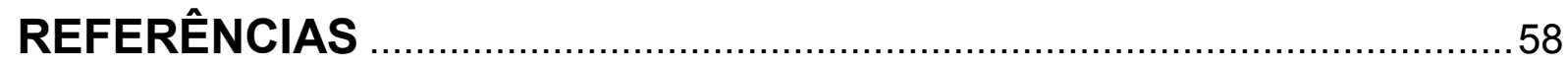

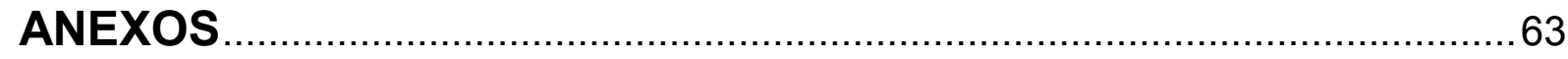




\section{INTRODUÇÃO}

A ATM é uma das regiões corpóreas de maior dificuldade na obtenção de imagens devido ao seu tamanho reduzido e por ser, ao menos parcialmente, encoberta pelas densas estruturas ósseas do crânio, sobretudo o rochedo petroso temporal, o que gera sobreposição de imagens (ALQUIVIST; ISBERG, 1999). Ainda assim, muito do conhecimento sobre anormalidades da ATM tem sido adquirido por meio dos avanços tecnológicos dos exames de imagem (CAVALCANTI, 2008).

Novos métodos para imagem da ATM têm sido relatados na literatura recentemente (CARA et al., 2007; CAVALCANTI, 2008; HINTZE; WIESE; WENZEL, 2007; PERRELLA et al., 2007;). As radiografias convencionais mostram-se limitadas para avaliação da cabeça da mandíbula devido à anatomia da região e a sobreposição e distorção de imagens (BÓSCOLO; ALMEIDA; PAGANINI, 1998; CARA et al., 2007). Tomografia computadorizada (TC) e ressonância magnética (IRM) são os métodos de escolha para avaliação do contorno das corticais ósseas, dinâmica articular e posição do disco na ATM (GRESS; ANDERS, 2005; HERNANDEZ, 1999; SALES; OLIVEIRA; CAVALCANTI, 2007; WESTESSON et al., 1987). A TC é um exame indicado devido a altas especificidade e sensibilidade, fundamental no diagnóstico, planejamento e tratamento das lesões ósseas (PERRELLA, 2006). Por meio da TC é possível visualizar o contorno da cabeça da mandíbula, sua posição na cavidade articular e o comprometimento das corticais ósseas relacionados a lesões ósseas e no caso de fraturas da cabeça da mandíbula (CHRISTIANSEN, et al., 1987a; UTUMI et al., 2008). As reconstruções parassagitais utilizando softwares específicos foram validadas para o planejamento de implante 
dentário por uma metodologia muito utilizada para este propósito (ABRAHAMS, 2001).

De acordo com Cara et al. (2006) em estudo comparando a validade de diferentes protocolos de imagens para TC singleslice utilizando cortes axiais e reconstruções multiplanares para análise de lesões simuladas em côndilo mandibular foram demonstradas que os protocolos utilizados são considerados acurados para lesões em côndilo.

A tomografia computadorizada possibilita cortes bem finos, de menos de $1 \mathrm{~mm}$ de espessura, dos componentes ósseos articulares da ATM, realizando um "rastreamento" detalhado da região, permitindo dessa forma um diagnóstico mais preciso (PERRELA, 2006).

Warnke, Carls e Sailer (1996) introduziram o programa de reconstrução multiplanar parasagital DENTASCAN, originariamente criado para implantes, para delineamento e avaliação quantitativa da Articulação Temporomandibular em plano sagital e coronal, usando dados a partir de cortes axiais originais da tomografia computadorizada.

O emprego da tomografia computadorizada tem sido muito utilizado no diagnóstico das diversas anormalidades ósseas que acometem a ATM, desde tumores até osteófitos (LUDLOW; DAVIES; TYNDALL, 1995; HUSSAIN et al., 2008). Santos e Cavalcanti (2002) relataram dois casos raros de osteossarcoma em cabeça de mandíbula detectados por meio da tomografia computadorizada, demonstrando sua eficácia. Os exames de tomografia computadorizada fornecem uma estimativa da distância entre os componentes ósseos da ATM com proporções em relação ao real de 1:1, eliminando o borramento observado em outras tomografias, possibilitando assim observar o posicionamento da cabeça da mandíbula na fossa 
mandibular. No entanto, alguns autores afirmam que não há evidências substanciais da importância da relação cabeça da mandíbula-fossa para o plano de tratamento.

Alterações ósseas como remodelamento e artroses são outras entidades que podem ser diagnosticadas com a tomografia da ATM. O remodelamento é uma mudança na forma e tamanho dos componentes ósseos articulares sem destruição ou degeneração dos tecidos moles que se situam sobre os mesmos. Já nas artroses há deterioração dos tecidos moles articulares, expondo as estruturas ósseas que se encontram abaixo destes (LARHHEIN; JOHANNESSEN 1995; WESTESSON et al., 1987).

Determinadas alterações osteolíticas que podem ocorrer na ATM são de difícil visualização em radiografias convencionais, como é o caso das erosões e osteófitos na cabeça da mandíbula, necessitando-se de exames de maior sensibilidade como a tomografia computadorizada (HUSSAIN et al., 2008). Segundo Marques (2001), a erosão apresenta uma prevalência de $2,4 \%$ do total de alterações da ATM.

Um dos maiores avanços em TC foi introdução da tomografia multislice. Esse novo tipo de scanner possui resolução submilimétrica, permitindo cortes de $0.5 \mathrm{~mm}$ com intervalo de reconstrução de $0.25 \mathrm{~mm}$ em apenas 0.4 segundos, o que é extremamente importante no eixo Z. Além de prover informações adicionais quando comparado à tomografia singleslice, a tomografia multislice permite a melhora na visibilidade de estruturas delgadas, proporcionando a eliminação de exposições adicionais para a obtenção de imagens transversais e coronais de alta qualidade devido à aquisição de dados com menor espessura de corte quando comparado a TC singleslice (JÄGER et al., 2005).

Diversos autores têm avaliado o uso de TC singleslice para avaliação de destruição óssea provocada por neoplasias malignas, entretanto estudos 
envolvendo a comparação de TC multislice, bem como a influência dos programas utilizados para análise e o papel destes na emissão de hipóteses diagnósticas ainda não foram relatados.

Muito se avançou na visualização das estruturas têmporo-mandibulares com a introdução de programas que proporcionam a manipulação dos dados originais obtidos durante a realização do exame de TC, obtendo então reconstruções multiplanares e parassagitais, porém utilizando TC multislice e em programas em uma estação de trabalho do próprio tomógrafo. 


\section{REVISÃO DE LITERATURA}

A Tomografia Computadorizada (TC) tem sido utilizada para avaliar a localização primária, extensão da afecção, e a invasão para estruturas adjacentes, principalmente com relação à infiltração do tumor nos tecidos moles e o envolvimento de estruturas adjacentes (ex: glândulas, nervos, vasos, ossos) (VAN DEN BREKEL et al., 1998; PERRELLA, 2006)

Diversos estudos têm sido encontrados na literatura referente a técnicas de imagens para articulação temporomandibular (ATM) (VANNIER, 2003). Estudos recentes demonstram um grande avanço tecnológico durante os anos para visualização desta região (HUSSAIN et al., 2008). No que se refere à modernização mais atual, foram encontrados estudos da tomografia computadorizada por feixe cônico (HINTZE; WIESSE; WENZEL, 2007). Uma breve revisão de literatura será comentada a seguir com ênfase da aplicabilidade da tomografia computadorizada na região da ATM.

\subsection{Tomografias computadorizada espiral}

Desde os trabalhos iniciais realizados por Hounsfield na década de 60 e que resultaram no prêmio Nobel em 1979, inúmeras inovações ocorreram no intuito de melhorias na forma de aquisições e avaliação dos dados obtidos, sendo reconhecidas 4 gerações de tomógrafos para TC que ficaram conhecidas como TC 
convencional. Nelas a fonte (tubo de raios X) e os detectores são acoplados e fazem movimento rotacional sobre o paciente que, não se movimenta durante a exposição. A cada exposição de um ponto anatômico a mesa (sobre a qual se encontra o paciente) se movimenta e pára. Porém esta técnica tinha como desvantagem o tempo total do exame que era muito longo e com isso o paciente se mexia gerando artefatos na imagem tomográfica. Estas desvantagens levaram ao desenvolvimento da TC espiral (CAVALCANTI, 2008; CAVALCANTI; VANNIER 1998; PERRELLA 2006;).

Com a introdução da tomografia computadorizada espiral em 1989, houve muitos progressos nas formas de aquisições de imagens, que auxiliavam na correção das limitações de sobreposições de imagens das radiografias convencionais e tomografia computadorizada convencional. Essas mudanças contribuíram para forma de obtenção de imagens mais rápidas, com menos tempo e baixo grau de irradiação nos pacientes expostos.

$\mathrm{Na}$ tomografia computadorizada espiral, o paciente é movimentado juntamente com a mesa em direção à fonte de raios $X$ durante uma contínua aquisição da imagem, simultaneamente, resultando num padrão espiral (helicoidal) do focus de raios $X$ relativos ao paciente. Desse modo, é possível melhorar qualidade da imagem nas reconstruções multiplanares (reconstruções em planos axial, coronal e sagital), bem como na reconstrução em 3D, pois quanto menor for espessura do intervalo de reconstrução melhor será a qualidade da imagem, reduzindo sensivelmente o tempo de trabalho se comparado com a tomografia computadorizada convencional (CAVALCANTI 2008).

Nos últimos anos de pesquisas e avanços tecnológicos muito tem se aplicado na tomografia computadorizada espiral, diversos softwares e modelos modernos de 
engenharia biomédica foram desenvolvidos para aperfeiçoar a melhora na qualidade de imagens. Nos dias atuais (ano de 2008) a tomografia computadorizada espiral se encontra em sua quinta geração.

\subsection{Aplicações da tomografia computadorizada nas regiões da articulação temporomandibular (ATM)}

A TC vem substituindo cada vez mais as radiografias convencionais no que se refere a exames de imagem para ATM por demonstrar vantagens quanto à diminuição de sobreposições de imagens e oferecendo maior precisão na qualidade da imagem.

Vários artigos científicos foram encontrados na literatura divulgando a aplicabilidade técnica da tomografia computadorizada na detecção de alterações na ATM. Serão abordados em uma breve revisão de literatura.

Helms et al. (1982), compararam a tomografia computadorizada com a artrografia na avaliação do menisco em articulações temporomandibulares (ATMs) com disfunção. Utilizaram, primeiro, a técnica da artrografia em dez pacientes com achados clínicos de deslocamento anterior do menisco. Duas semanas depois, os mesmos pacientes foram submetidos à técnica da tomografia computadorizada com aparelho GE $8800 \mathrm{CT} / \mathrm{T}$, estando com a boca aberta e um bloco de mordida localizado para eliminar movimentos involuntários. Foram feitas depois comparações entre os dados obtidos com as duas técnicas. Os autores concluíram que a 
tomografia computadorizada deve substituir a artrografia para exame da disfunção de ATM relacionada ao disco.

Manzione et al. (1984) fizeram um estudo para correlacionar a tomografia computadorizada de ATMs de cadáver com a dissecção anatômica correspondente, e também comparar a tomografia computadorizada com a artrografia. Examinaram quatro ATMs de dois cadáveres com a técnica de tomografia computadorizada em tomada sagital com aparelho SIEMENS SOMATOM 2. As tomadas foram feitas de medial para lateral com cortes contínuos de $2 \mathrm{~mm}$, estando primeiramente a boca aberta e depois fechada. Depois, as quatro ATMs foram dissecadas. Também foram feitos exames de tomografia computadorizada em 51 ATMs de 47 pacientes deitados em supinação na mesa e a cabeça localizada lateralmente ao gantry. A mesma técnica de tomada radiográfica e aparelhos dos experimentos anteriores foram utilizados e depois os resultados comparados com a artrografia. Os autores puderam concluir que a tomografia computadorizada digital é eficaz, não invasiva, e que deve ser o primeiro exame radiográfico de investigação de disfunções da ATM, tornando-se necessária a artrografia somente quando o menisco não é visível no exame anterior.

Thompson et al. (1984) realizaram um estudo na qual utilizaram uma tomografia computadorizada de alta resolução para avaliação de ATM de 43 pacientes. No estudo sinais indiretos de deslocamento de disco foram encontrados em $80 \%$ das articulações afetadas. Sinais esses descritos como: remodelamento da superfície articular pelo posicionamento anormal do disco durante a função, remodelação osteofítica e alteração degenerativa da superfície articular, alterações de espaço entre superfície articular óssea, assimetria do ramo mandibular com encurtamento do lado envolvido, migração do processo coronóide do lado envolvido 
e assimetria do músculo pterigóide lateral. Os autores enfatizam a importância da visualização das estruturas adjacentes que compõem a região da ATM. Na conclusão citam que os radiologistas devem ser familiares com a anatomia e a patologia da ATM para realizar diagnóstico radiológico apropriado podendo incluir a tomografia computadorizada em alta resolução.

Christiansen et al. (1987b) examinaram 25 pacientes por meio de tomografia computadorizada, medindo os espaços articulares da ATM, correlacionando, dessa forma, a posição condilar com a posição do disco. Encontraram diferenças significativas entre a posição do disco e espaços articulares, com maior freqüência nos intervalos articulares ântero-superior e superior. Concluíram, então, que em articulações com desarranjos internos, onde há estreitamento dos espaços articulares, esse pode estar localizado e não necessariamente em toda a extensão da ATM.

Kirk Jr (1989) examinou 35 ATMs por meio de tomografias corrigidas digitalmente comparando-as com imagens de ressonância magnética analisando a posição condilar e alterações ósseo-degenerativas. No estudo por ressonância magnética, 10 ATMs apresentaram posicionamento de disco normal, ao mesmo tempo nove destas mostraram os côndilos em posição central na fossa articular. Foram encontradas sete ATMs com deslocamento e ampla variação do posicionamento condilar. Do total de ATMs estudadas 18 apresentaram evidências de deslocamento do disco sem redução nas imagens por ressonância magnética. Destas 18 ATMs, oito apresentaram côndilo em posição central na fossa articular, enquanto as outras mostraram evidências de alterações do posicionamento condilar. O espaço articular diminuiu na média com evidência de deslocamento do disco. Somente as articulações com deslocamento do disco sem redução mostraram 
evidências de alterações ósseo-degenerativas. Há necessidade de realização de estudos com amostra maior para investigar esta tendência encontrada, tendo ocorrido diminuição do espaço articular na presença de deslocamento de disco. O autor concluiu que a tomografia convencional corrigida pode sugerir a presença de deslocamento do disco ou desarranjos internos significativos.

Tanimoto et al. (1990), compararam a tomografia computadorizada com a tomografia convencional para o diagnóstico de alterações ósseas na articulação temporomandibular. Utilizaram quinze ATMs direitas, removidas de cadáveres com data de óbito recente, que foram submetidas a exames de tomografia computadorizada com cortes de $2 \mathrm{~mm}$ de espessura. Aproximadamente de 7 a 10 cortes foram obtidos de sagital, e de 5 a 7 de frontal. Os mesmos espécimes foram utilizados para tomadas sagitais e frontais de tomografia convencional. Os autores concluíram que a tomografia convencional é superior à tomografia computadorizada direta no diagnóstico de alterações ósseas estruturais, ajudando no diagnóstico de doenças da ATM.

De Bont et al. (1993) fizeram um estudo para mostrar a utilidade da TC para o diagnóstico diferencial das desordens da ATM Não relacionados a anormalidades do disco articular. Foram obtidas TC em planos sagitais de 16 pacientes portadores de desordens da ATM em tecidos duros. Os resultados obtidos foram analisadas de acordo com diagnóstico diferencial das desordens da ATM. Segundo os autores a TC tem grande potencial para visualização das imagens intra e extra capsulares de desordens da ATM de tecido duro e enfatizam que a TC não é o melhor método de imagem para visualizar a posição e forma do disco. A TC é uma grande modalidade para diagnóstico diferencial das desordens da ATM. 
Gynther, Tronje e Holmlund (1996) fizeram um estudo comparando radiografias transcranianas individualizadas com tomografias corrigidas sagitais e frontais de vinte pacientes portadores de osteoartrite generalizada, e de 21 pacientes com artrite reumatóide, apresentando envolvimento da ATM. No grupo de pacientes com artrite reumatóide, $71 \%$ das ATMs mostraram alterações estruturais, e no grupo com osteoartrite generalizada ocorreu o mesmo em $80 \%$ das ATMs. Não foram encontrados quaisquer sinais radiográficos, no entanto, osteófitos, aplainamento do côndilo e redução dos espaços articulares foram observados com freqüência maior em ATM com osteoartrite generalizada. Já erosões no côndilo foram mais comuns em ATMs cujos pacientes apresentavam artrite reumatóide. Em pacientes com osteoartrite generalizada, os aspectos radiográficos foram similares aos aspectos encontrados em pacientes com osteoartrite na forma comum da ATM do que os aspectos encontrados em pacientes com artrite reumatóide.

Warnke, Carls e Sailer (1996) fizeram um estudo para investigar a aplicabilidade de um programa de reconstrução multiplanar (DENTASCAN) para delineamento e avaliação quantitativa da articulação temporomandibular em plano sagital e coronal, usando dados de tomografia computadorizada axial. O resultado de imagens foi comparada com tomografia linear e tomografia computadorizada sagital e coronal. Foram obtidas em 11 pacientes tomografias lineares e computadorizadas de ATM em plano axial, coronal e sagital. Os cortes axiais da tomografia computadorizada foram então reconstruídos em plano oblíquo frontal e sagital, de acordo com o ângulo condilar horizontal, em software DENTASCAN. De cada paciente, e uma em cada três imagens, 14 medidas foram feitas e 24 caracterizações foram investigadas. Os autores concluíram que a reconstrução de cortes axiais de tomografia computadorizada de ATM, usada com software 
DENTASCAN, mostrou várias vantagens sobre a tomografia linear, apesar do aumento da dose de radiação, tempo e custo.

El Hakim e Metwalli (2002), estudaram 33 pacientes que foram tratados para anquilose de ATM comparando os achados radiográficos e clínicos pré-operatórios com os encontrados na cirurgia e propuseram uma nova classificação. Os exames radiográficos aos quais se submeteram os pacientes foram: radiografia panorâmica e tomografia computadorizada com cortes axiais e coronais. Os achados durante a cirurgia foram comparados com as características das imagens. A tomografia computadorizada em coronal após contraste foi a melhor modalidade de imagem para o planejamento cirúrgico, bem como demonstrou a relação anatômica entre a anquilose e as estruturas vitais circundantes, particularmente onde os ossos esfenóide e temporal estavam envolvidos. Os autores sugerem que o planejamento cirúrgico deva ser baseado na tomografia computadorizada em cortes axiais e coronais.

Tsuruta et al. (2003) com o objetivo de investigar a relação entre a densidade do teto da fossa glenóide da ATM e a existência e tipos de alterações ósseas condilares, estudaram 37 pacientes com desordem temporomandibular por meio da tomografia computadorizada espiral. Estas alterações foram classificadas em 4 tipos: sem alteração (24 ATMs); aplainamento (19 ATMs); osteófito (13 ATMs) e erosão (18 ATMs). O teto da fossa glenóide foi significativamente mais denso em articulações com alterações ósseas do que sem alterações. Eles concluíram que a formação óssea no teto da fossa articular poderia ajudar a resistir o estresse aumentado na ATM acompanhado de alteração condilar óssea, especialmente a erosão. 
Yamada et al. (2004) investigaram em seu estudo, a relação entre a inclinação da eminência articular e doenças da ATM em pacientes submetidos à cirurgia ortognática com sinais e sintomas de desordem temporomandibular. Vinte e um pacientes do gênero feminino foram examinados por meio de tomografia computadorizada espiral, antes do tratamento. Os resultados sugerem que o aplainamento da eminência poderia ocorrer durante as alterações, desde erosões até formação de osteófito, e de deslocamento anterior de disco com redução até sem redução. Estas ocorrências representam adaptação do côndilo, disco articular e eminência articular perante variações de carga na articulação.

Tsiklakis, Syriopoulos, Stamatakis (2004) realizaram um estudo com uma nova técnica de tomografia computadorizada por feixe cônico para avaliação da articulação temporomandibular. No estudo relatam que esta técnica permite usar um curto período de aquisição de exame e cerca de 6 vezes menor da dose de radiação comparada com tomógrafos convencionais, realizando reconstruções de alta qualidade de imagem diagnóstica. Segundo os autores pode ser considerada a técnica de imagem de escolha para investigação da região da articulação temporomandibular.

Gaia e Cavalcanti (2005) realizaram um estudo dos diferentes protocolos em tomografia computadorizada para afecções ósseas da articulação temporomandibular. Enfatizando que a TC utilizando imagens axiais e reconstruções multiplanares (RMP) pode ser considerada como imagem padrão para visualização da ATM, particularmente na identificação da integridade das estruturas quando da suspeita de alterações patológicas, na confirmação da extensão de uma alteração já diagnosticada, no planejamento e na avaliação do tratamento das injúrias ósseas da 
ATM. Segundo os autores a 3D-TC pode ser considerada um importante adjunto, para melhor esclarecimento do envolvimento de estruturas anatômicas.

Honda et al. (2006) compararam a confiabilidade da tomografia computadorizada por feixe cônico e tomografia computadorizada helicoidal para a detecção de anomalias ósseas do côndilo mandibular, usando observações macroscópicos com o padrão ouro. No estudo foram utilizados 21 articulações temporomandibulares espécime da autópsia que foram analisadas na tomografia computadorizada por feixe cônico e tomografia computadorizada helicoidal, a presença de erosões na cortical ou osteófitos e escleroses. Na conclusão os autores enfatizam que a tomografia computadorizada por feixe cônico é um método diagnóstico alternativo de baixo custo e diminuição da dose, eficaz para a avaliação dos componentes ósseos do TMJ, mas que mais estudos são necessários com grandes quantidades de ATM e análises de componentes temporais para confirmar que a tomografia computadorizada por feixe cônico é pelo menos equivalente a tomografia computadorizada helicoidal para avaliação do diagnóstico de diferentes condições da ATM.

Um estudo recente de Hintze, Wiese e Wenzel (2007) comparou a acurácia diagnóstica de imagens de tomografia computadorizada por feixe cônico com tomgrafias convencionais para detecção de alterações morfológicas da ATM. No estudo de vários tipos de alterações morfológicas em relação a cabeça da mandíbula e o tubérculo articular avaliados separadamente resultaram sem diferenças significativas entres as modalidades de imagens, com exceção dos defeitos ósseos no tubéculo articular examinados pelas imagens frontais isoladas, onde a especificidade com a tomografia convencional foi significantemente alta em relação a tomografia computadorizada por feixe cônico. Na detecção de todas 
alterações morfológicas em relação a ambos, cabeça da mandíbula e tubérculo articular mostrou uma alta significativa acurácia para tomografia convencional do que a tomografia por feixe cônico utilizando imagens laterais isoladas, mas que não houve diferenças significativas entre as duas modalidades utilizando as imagens frontais isoladas e lateral e frontal combinadas. Mas os autores enfatizam que essas diferenças de especificidade de 3\% não trariam nenhuma conseqüência na clínica.

Cara et al. (2007) realizaram um estudo para avaliar e comparar a validade dos diferentes protocolos de imagens (single e multislice TC) na análise de lesões simuladas na cabeça da mandíbula. No estudo foram utilizadas 15 mandíbulas secas, onde foram realizadas perfurações utilizando brocas esféricas de uso odontológico e os mesmos foram submetidos a exames de TC single slice e multislice. Os examinadores avaliaram a presença ou ausência de destruição óssea e sua localização em cada um dos quatro protocolos estabelecidos (1-single sliceaxial, 2- multislice axial, 3- single slice-RMP, 4- multislice-RMP). Na conclusão eles citam que todos os protocolos de imagem foram considerados acurados para avaliação de lesões na cabeça da mandíbula. A associação das imagens axiais com reconstruções multiplanares (RMP) utilizando tomografia computadorizada multislice demonstrou alta acurácia em relação ao protocolo single-slice. E que um novo protocolo de imagem foi estabelecido para diagnóstico dessas lesões na cabeça da mandíbula.

Koyama, Nishiyama e Hayashi (2007) avaliaram desordens têmporomandibulares de 516 indivíduos totalizando 1032 articulações têmporo-mandibulares pela tomografia computadorizada helicoidal. No estudo foi proposta uma classificação das imagens em reconstruções multiplanares (RMP) do CT helicoidal em 5 tipos: N-no bone change (sem alteração óssea); F-flattening (aplainado); E- 
erosion with or without roughening (erosão com ou sem superfície áspera); Ddeformity (deformidade); S- Deformity accompanied by erosion with or without roughening (deformidade acompanhada de erosão com ou sem superfície áspera). Os autores concluem que a classificação é conveniente para avaliação de alterações ósseas na ATM.

Perrela et al. (2007) avaliaram a validade de dois protocolos, em secções axiais, em lesões simuladas de mandíbula. No estudo dois protocolos de TC (singleslice e multislice) foram obtidos em mandíbulas secas em que foram feitas as perfurações, simulando lesões. No resultado observaram que a sensibilidade e a especificidade foram de $100 \%$ para detecção de lesões para ambos os protocolos, mas a detecção do número de lojas das lesões multiloculares e a localização e detecção de invasão medular obtiveram valores reduzidos em sua validade, o que foi influenciado pelo protocolo de aquisição. Na conclusão os autores relatam que secções axiais e reconstruções mais finas foram mais efetivas na detecção de invasão medular precoce e lojas tumorais, onde protocolos mais espessos não foram considerados apropriados para a detecção de lesões multiloculares e estágios iniciais de invasão medular.

Sales, Oliveira e Cavalcanti (2007) apresentaram um caso simultâneo de côndilo mandibular bífido e anquilose temporomandibular. No estudo enfatizam que a TC foi uma ferramenta válida para o diagnóstico do côndilo mandibular bífido e anquilose temporomandibular e que as imagens obtidas foram de grande valia para ilustrar a relação de estruturas vitais da base do crânio a massa anquilótica do lado acometido e detalhamento dos côndilos bífidos. E que é essencial a condução da avaliação de CT em patologias precoces da ATM. 
Utumi et al. (2008), descreveram um caso raro de síndrome de SAPHO (sinovite, acne, pustolose, hiperostose, osteíte), portador de anquilose de ATM bilateral. No estudo os autores enfatizam que a tomografia computadorizada contribuiu para melhor visualização da detecção das estruturas envolvidas evitando sobreposições de imagens e serviu de complemento juntamente com outros exames ao diagnóstico final e planejamento cirúrgico corretivo da anquilose.

Hussain et al. em (2008) avaliaram e estudaram a habilidade dos diferentes técnicas diagnósticas de imagem para diagnóstico da presença de erosões e osteófitos em regiões da articulação têmporo-mandibular. No estudo fizeram a comparação de diferentes técnicas de imagem: imagens panorâmicas, tomografia sagital corrigida axialmente, imagem de ressonância magnética sagital, ultrasom alta resolução e tomografia por feixe cônico. Na conclusão os autores relatam que atualmente a tomografia sagital corrigida axialmente é a modalidade de escolha para diagnóstico de erosões e osteófitos na ATM, mas que a combinação de diferentes técnicas radiográficas é mais acurada para diagnosticar erosões e osteófitos na ATM do que uma única modalidade de imagem. Enfatizam que estudos diagnósticos simultâneos de diferentes técnicas de imagens disponíveis são necessários para a confirmação da patologia. 


\section{PROPOSIÇÃO}

Este trabalho consiste na análise de lesões ósseas simuladas na cabeça da mandíbula por meio da tomografia computadorizada multislice, bem como comparar a validade das imagens obtidas através de diferentes protocolos. 


\section{MATERIAL E MÉTODOS}

Conforme resolução do CONEP 196/96 e aprovação do Comitê de Ética em Pesquisa da FOUSP (Parecer de aprovação 141/07-anexo A) serão utilizadas, no presente estudo, as mesmas 15 mandíbulas dentadas maceradas que já foram escaneadas e utilizadas no mesmo projeto do acervo da Universidade Gama FilhoRJ, Rio de Janeiro, nas quais foram realizadas perfurações que atinjam a cortical ou medular dos pólos lateral, medial, anterior, posterior e da região central superior da cabeça da mandíbula totalizando 5 áreas demarcadas com número de 1 a 5 na cabeça da mandíbula (Figura 4.1). As lesões serão simuladas através do emprego de pontas diamantadas esféricas de diferentes diâmetros em alta rotação em um total de 3 brocas da marca Jet-Carbide burs (n FOGS 1, FGOS 3, FGOS 6) que simularão lesões ósseas (Figura 4.2). As mandíbulas preparadas serão submetidas a exame em tomógrafo computadorizado multislice (Figura 4.3). 


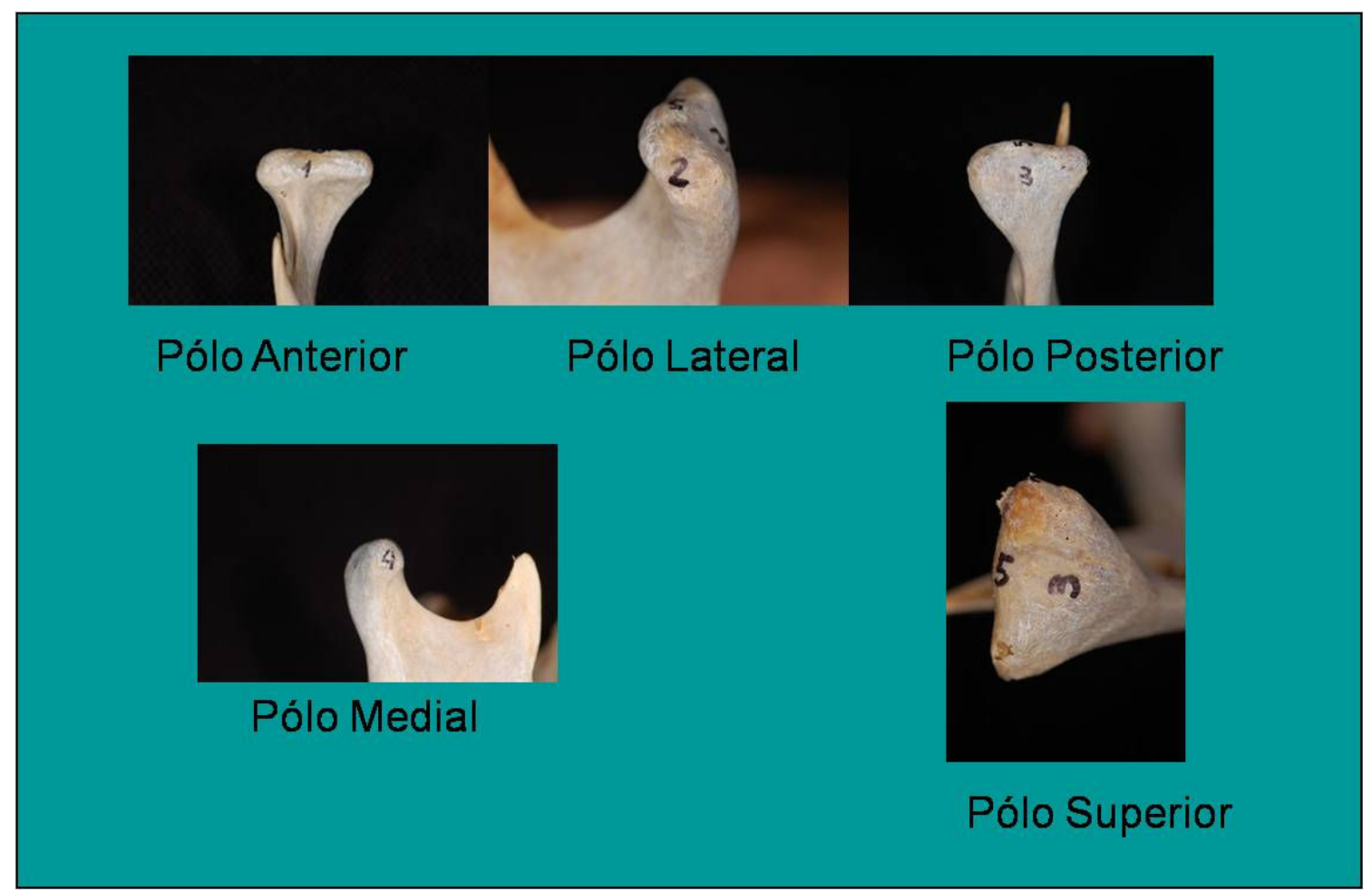

Figura 4.1 - Localização onde serão feitas as perfurações 1-5

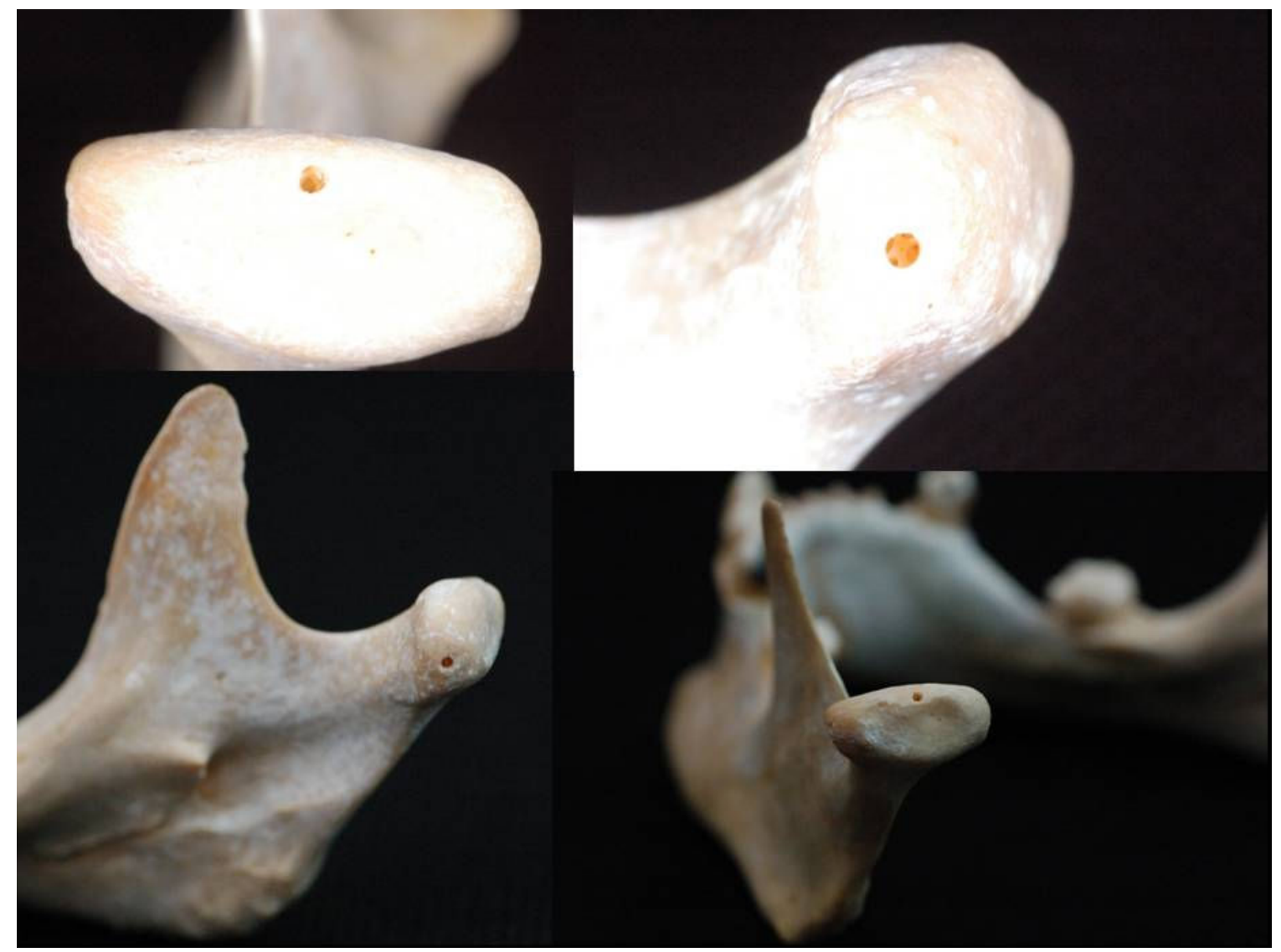

Figura 4.2 - Perfurações localizadas em diferentes pólos 


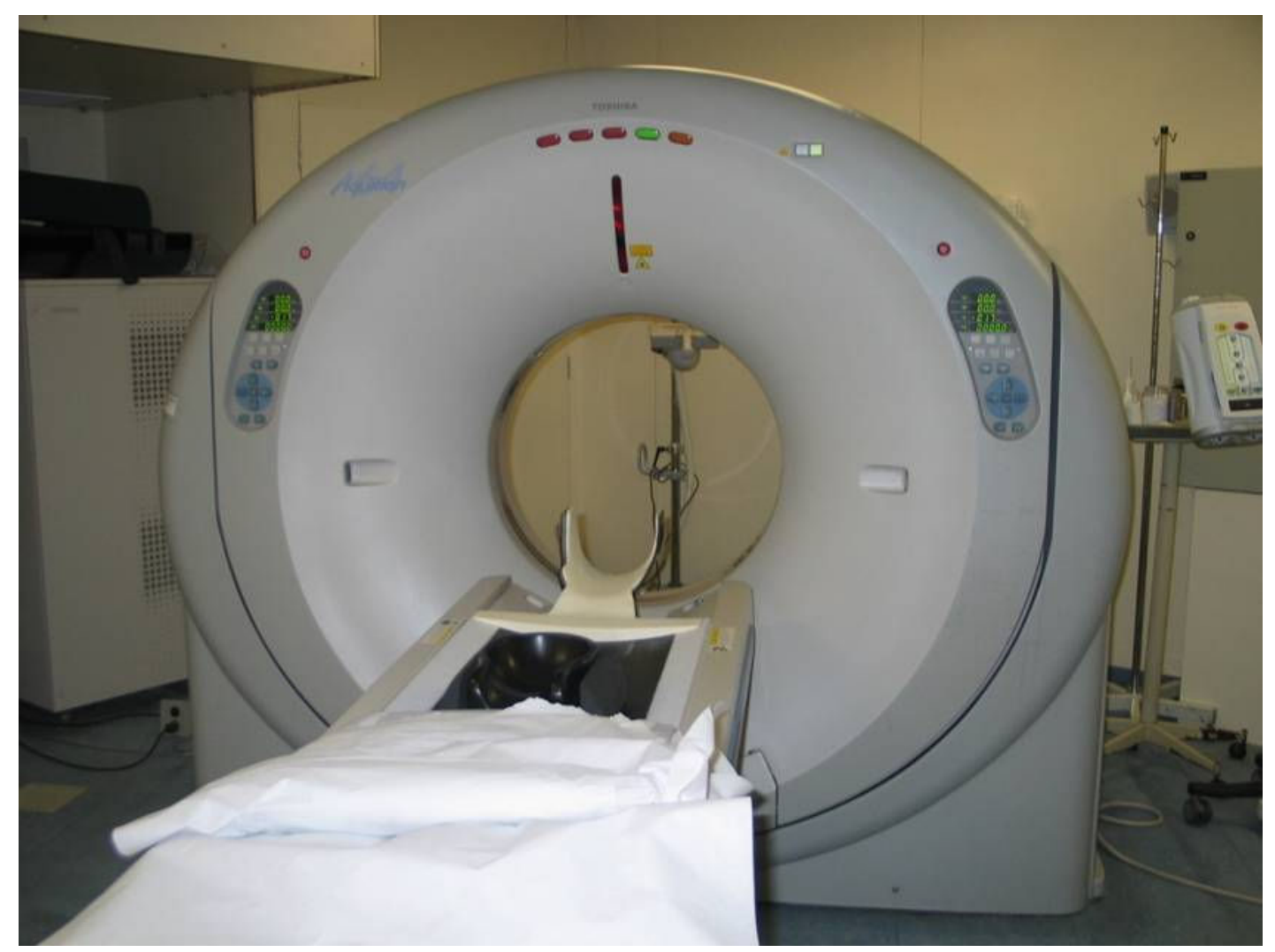

Figura 4.3 -Tomografia computadorizada espiral multislice 64 cortes/0,5 segundo (Aquilion, Toshiba Medical Systems, Tustin, CA, EUA)

Para padronização da metodologia empregada e para execução do trabalho inédito todas as mandíbulas foram escaneadas por meio de cortes axiais, desde a sua base até a região da cabeça da mandíbula. Após a obtenção do escanograma, o plano de aquisição axial foi estabelecido paralelamente à base da mandíbula até a região da cabeça da mandíbula (Figura 4.4). 


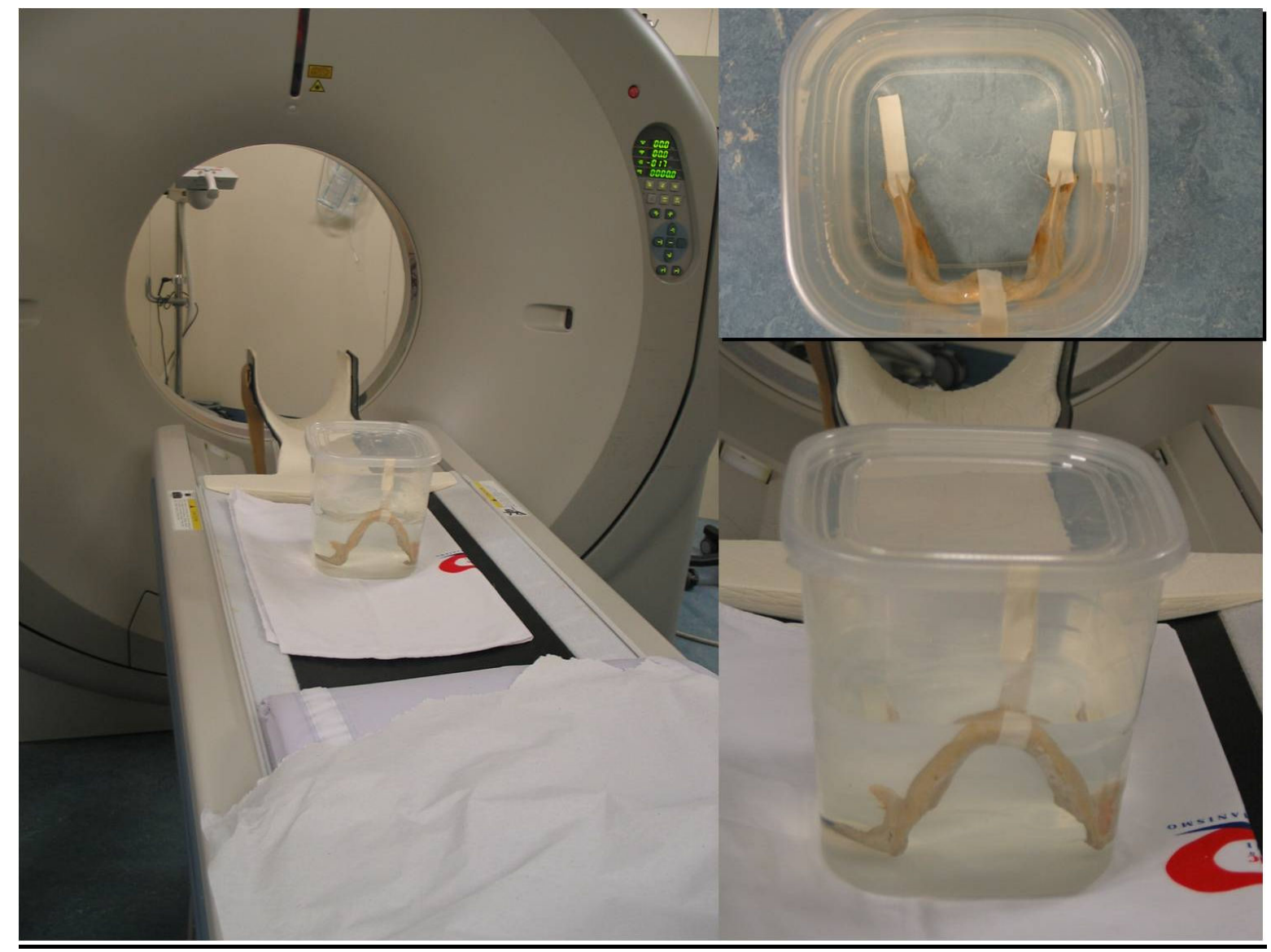

Figura 4.4 - Posicionamento da mandíbula no interior do recipiente com água simulando o posicionamento do paciente no tomógrafo

\section{Aquisição tomográfica MULTISLICE:}

- Tomógrafo computadorizado espiral multislice 64 cortes/0,4 segundos (Aquilion, Toshiba Medical Systems, Tustin, CA, EUA) instalado no Departamento de Imagem (Setor de tomografia computadorizada) do Instituto do Coração da Faculdade de Medicina da Universidade de São Paulo (InCor-FMUSP). (autorização do Departamento em anexo).

- Protocolo de aquisição das imagens:

Espessura de corte: $0.5 \mathrm{~mm}$

Incremento de mesa: $0.3 \mathrm{~mm}$ 
Tempo: 0.4 segundos

Matrix: $512 \times 512$

Regime de trabalho: $120 \mathrm{kVp}$ e $300 \mathrm{~mA}$

Campo de visualização (FOV): $18 \mathrm{~cm}$

Durante esta etapa realizada, as imagens das mandíbulas foram adquiridas em formato DICOM - opção RAW, que permitem a sua utilização posterior em diversos protocolos posteriores de avaliação definidos pelo operador do(s) programa(s) a ser (em) utilizado(s),

As imagens obtidas foram arquivadas formato DICOM (Digital Imaging Comunication in Medicine), foram armazenadas em CDs e enviadas para uma estação de trabalho independente contendo o programa RadioStudio (versão 1.7Companhia Anne solutions, São Paulo, Brasil) para a obtenção de reconstruções multiplanares e parassagitais dos côndilos mandibulares (Figura 4.5). Estas foram analisadas independentemente por 02 examinadores (aluno de mestrado- ERU e um doutorando) previamente calibrados pelo orientador do projeto. Uma terceira pessoa (aluno de Doutorado orientado do coordenador do projeto) realizou as perfurações em diferentes áreas de acordo com as áreas demarcadas. Os examinadores das imagens não tiveram nenhuma informação a respeito das perfurações na cabeça da mandíbula. Foram avaliadas, visualizações e localizações das perfurações nas imagens em momentos distintos, por meio do programa RadioStudio (versão 1.7Companhia Anne solutions, São Paulo, Brasil), utilizando janela para tecido ósseo. Tal avaliação foi realizada em uma estação de trabalho independente no Laboratório de Imagem 3D (LABI-3D) (www.fo.usp.br/labi3d) da Faculdade de Odontologia da 
Universidade de São Paulo - FOUSP. A sistemática de interpretação das imagens das mandíbulas seguiu a seguinte rotina para todos os examinadores envolvidos, de maneira alternada e às cegas, com intervalo de 07 dias consecutivos para subseqüente avaliação de imagens. A seqüência de análise das imagens a ser executada obedeceu aos seguintes protocolos:

1. Reconstruções multiplanares: imagens axiais, coronais e sagitais (Figura 4.5).

2. Reconstruções parassagitais (Figuras 4.6, 4.7, 4.8).

Dois examinadores analisaram as imagens, 02 vezes o aluno de mestrado (observador 1 e $1^{\prime}$ ), e 1 vez o aluno de doutorado (observador 2), independentemente com intervalo de 1 semana para cada observador. Para análise das lesões na TC versus o padrão ouro (mandíbula macerada) foi avaliada a ausência ou presença de destruição óssea e sua localização em cada protocolo. 


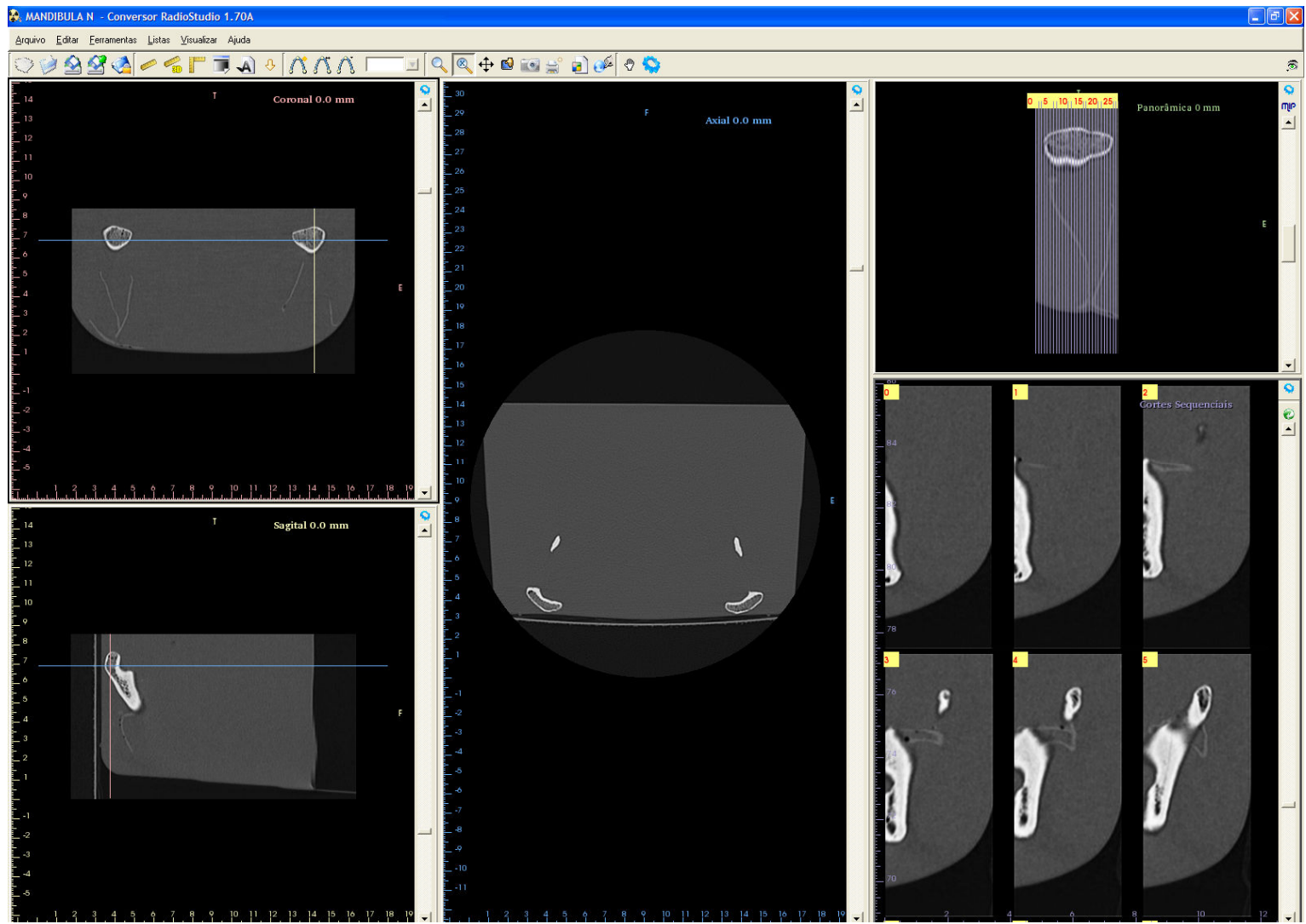

Figura 4.5 - Tela do programa de visualização de imagens do programa RadioStudio 


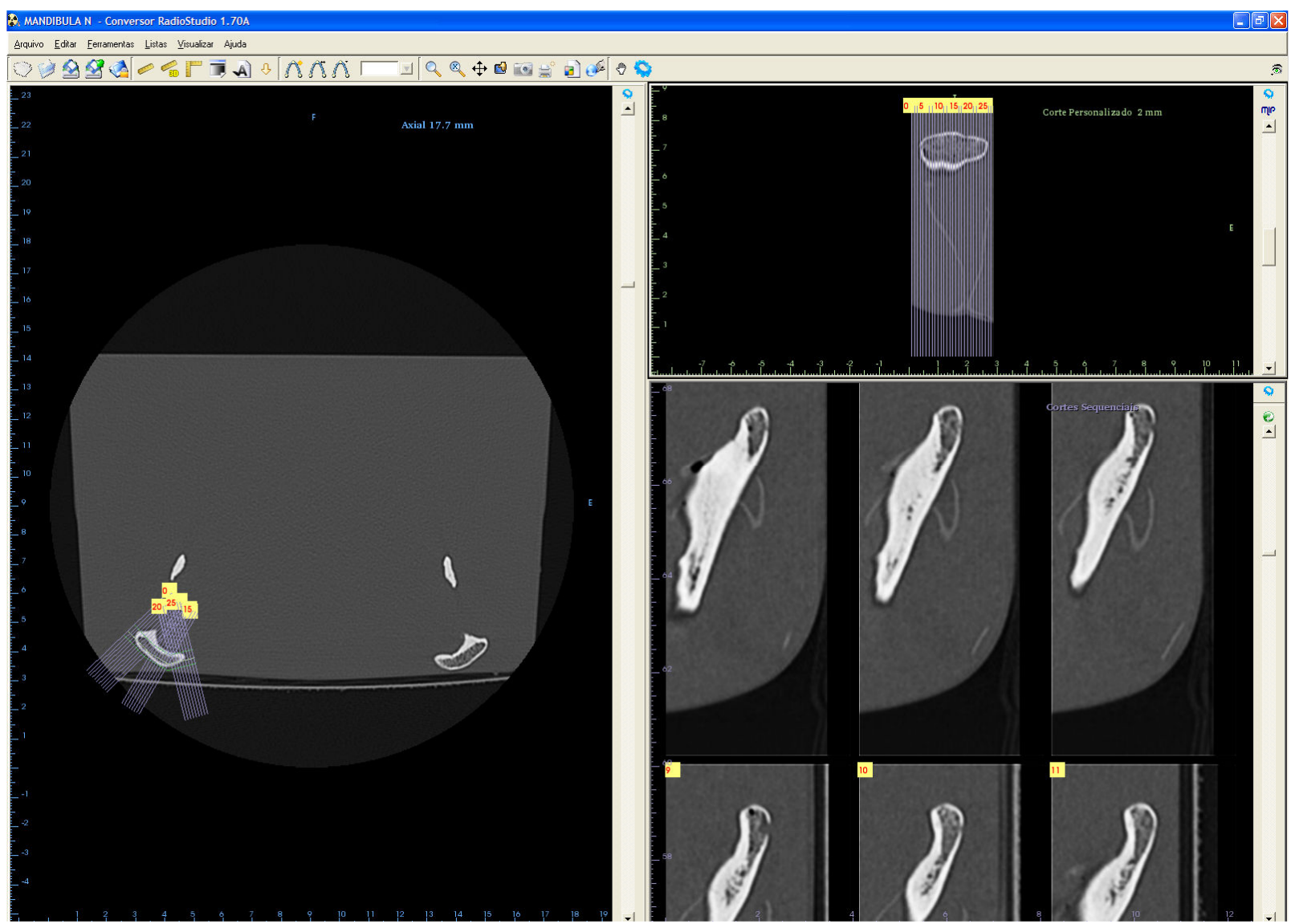

Figura 4.6 -Imagem das demarcações parassagitais e visualização dos cortes reconstruídos pelo programa

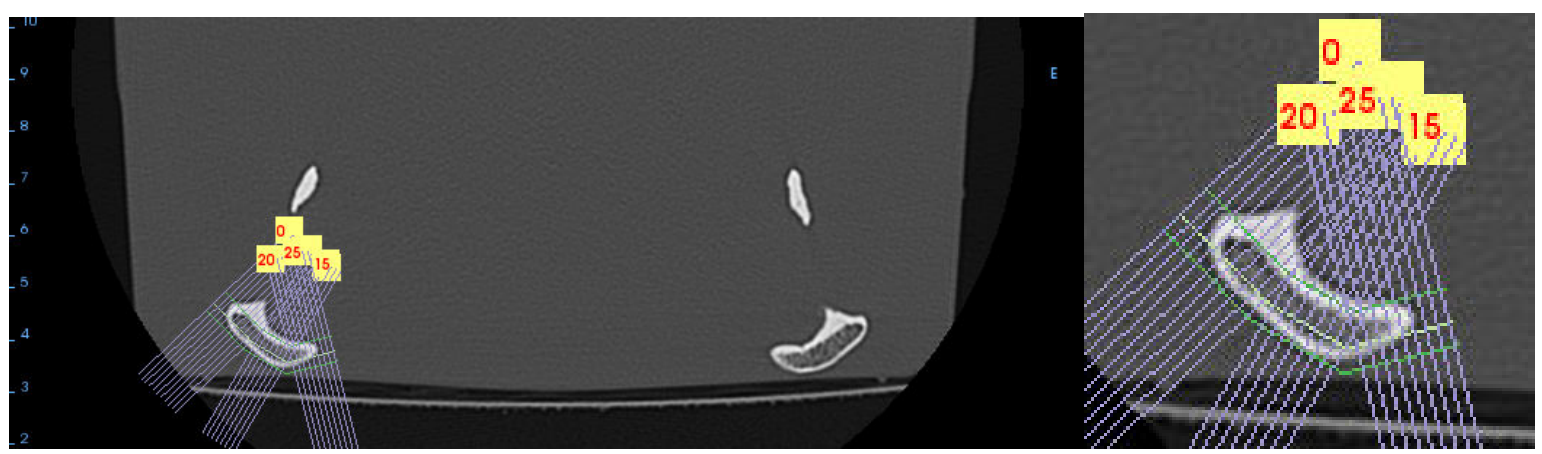

Figura 4.7 - Demarcações parassagitais no sentido látero-medial 


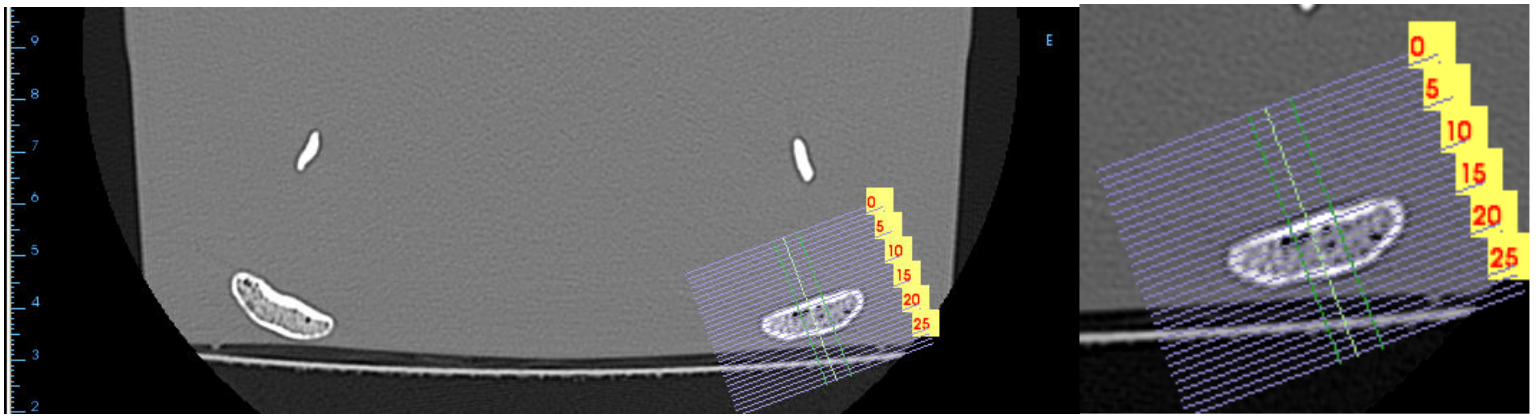

Figura 4.8 - Demarcações parassagitais no sentido ântero-posterior 


\section{RESULTADOS}

A- Critérios para análise das lesões simuladas na cabeça da mandíbula:

Foram analisadas as presenças de lesões simuladas nas reconstruções multiplanares: imagens axiais, coronais e sagitais e reconstruções parasagitais. A análise foi comparada entre os observadores 1 e 1' (aluno de mestrado-autor do projeto) e 2 (doutorando) com o padrão ouro.

Para análise estatística foram usados o método Estatística de Kappa, teste de Validade (sensibilidade-especificidade) e teste qui-quadrado, por meio do programa denominado SPSS versão 15.0 para Windows (Statistical Package for Social Science, Chicago, ILL). Foram utilizados os testes de concordância e razão do teste kappa para analisar os índices de positividade para comparação entre os dois examinadores. Calculou-se a porcentagem por pólo e global de concordância e o índice kappa. Porcentagem de concordância é a porcentagem de diagnósticos positivos e negativos em concordância com os examinadores. O índice kappa é o parâmetro de concordância que leva em conta a concordância ao acaso. Kappa varia de -1 a +1 . O valor zero apresenta concordância casual, valores positivos representam índice de concordância além da concordância casual. Foi utilizado o teste qui-quadrado para analisar a proporção de concordância e discordância entre os dois examinadores nos dois protocolos. 
Tabela 5.1 - Tabela da análise das imagens axial, coronal, sagital: Kappa intra e inter observadores

\begin{tabular}{l|c|c|c|c|c}
\hline \multicolumn{1}{c|}{ Kappa } & Medial & Lateral & Anterior & Posterior & Superior \\
\hline Obs1 $\times$ Obs1' & 0,42 & 0,56 & 0,53 & 0,91 & 0,51 \\
$\mathrm{p}$ & 0,003 & $<0,001$ & $<0,001$ & $<0,001$ & 0,003 \\
& & & & & \\
Obs1 x Obs2 & 0,79 & 0,92 & 0,73 & 0,49 & 0,73 \\
$\mathrm{p}$ & $<0,001$ & $<0,001$ & $<0,001$ & 0,004 & $<0,001$ \\
Obs1'x Obs2 & 0,40 & 0,67 & 0,79 & 0,56 & 0,63 \\
$\mathrm{p}$ & 0,008 & $<0,001$ & $<0,001$ & 0,001 & $<0,001$ \\
\hline
\end{tabular}

1) Observamos que a melhor concordância obtida dentro do mesmo observador esta no pólo posterior (kappa=0,91). A menor concordância se observa no pólo medial (kappa=0,42).

2) Observamos que a menor concordância entre os observadores (na primeira medida do observador 1$)$ foi obtida no pólo posterior $(k a p p a=0,49)$ e a maior no pólo lateral (kappa=0,92).

3) Observamos que a menor concordância entre os observadores (na segunda medida do observador 1$)$ foi obtida no pólo medial $($ kappa $=0,40)$ e a maior no pólo anterior (kappa=0,79).

Tabela 5.2 - Tabela da análise das imagens parassagitais: Kappa intra e inter observadores

\begin{tabular}{l|c|c|c|c|c}
\hline \multicolumn{1}{c|}{ Kappa } & Medial & Lateral & Anterior & Posterior & Superior \\
\hline Obs1 $\times$ Obs1' & 0,38 & 0,66 & 0,59 & 0,53 & 0,67 \\
$\mathrm{p}$ & 0,013 & $<0,001$ & $<0,001$ & 0,001 & $<0,001$ \\
& & & & & \\
Obs1 x Obs2 & 0,38 & 0,92 & 0,66 & 0,53 & 0,61 \\
$\mathrm{p}$ & 0,009 & $<0,001$ & $<0,001$ & 0,001 & $<0,001$ \\
Obs1'x Obs2 & 0,49 & 0,60 & 0,93 & 0,81 & 0,76 \\
$\mathrm{p}$ & 0,003 & $<0,001$ & $<0,001$ & $<0,001$ & $<0,001$ \\
\hline
\end{tabular}


1) Observamos que a melhor concordância obtida dentro do mesmo observador esta no pólo superior (kappa=0,67). A menor concordância se observa no pólo medial (Kappa=0,38).

2) Observamos que a menor concordância entre os observadores (na primeira medida do observador 1$)$ foi obtida no pólo medial (kappa $=0,38)$ e a maior no pólo lateral (kappa=0,92).

3) Observamos que a menor concordância entre os observadores (na segunda medida do observador 1 ) foi obtida no pólo medial (kappa $=0,49)$ e a maior no pólo anterior (kappa=0,93).

Analisando os kappas dentro do mesmo observador vemos que o menor valor se encontra no pólo medial nas imagens parassagitais e o maior no pólo posterior das axiais. Nos pólo medial e posterior os kappas são maiores nas imagens axiais e nos pólos lateral, anterior e superior nas imagens parassagitais.

Analisando os kappas entre observadores vemos que:

Na primeira medida do observador 1, somente no pólo posterior temos um kappa maior nas imagens parassagitais em relação as axiais.

Na segunda medida do observador 1 , somente no pólo lateral temos valor maior nas imagens axiais, coronais e sagitais do que nas imagens parassagitais.

Tabela 5.3 - Tabela das análises das imagens axiais, coronais, sagitais: Kappa em relação ao padrão ouro

\begin{tabular}{l|c|c|c|c|c}
\hline Kappa & Medial & Lateral & Anterior & Posterior & Superior \\
\hline Obs1 & 0,42 & 0,75 & 0,47 & 0,56 & 0,63 \\
$\mathrm{p}$ & 0,003 & $<0,001$ & 0,003 & 0,001 & $<0,001$ \\
Obs1' & 0,52 & 0,82 & 0,62 & 0,63 & 0,90 \\
$\mathrm{p}$ & 0,002 & $<0,001$ & $<0,001$ & $<0,001$ & $<0,001$ \\
& & & & & \\
Obs2 & 0,57 & 0,84 & 0,72 & 0,73 & 0,73 \\
$\mathrm{p}$ & $<0,001$ & $<0,001$ & $<0,001$ & $<0,001$ & $<0,001$ \\
\hline
\end{tabular}


1) O observador 1, na primeira medida, apresentou a maior concordância com o padrão-ouro no pólo lateral $($ kappa $=0,75)$ e a menor no pólo medial (kappa=0,42).

2) O observador 1 , na segunda medida, apresentou a maior concordância com o padrão-ouro no pólo superior $(k a p p a=0,90)$ e a menor no pólo medial (kappa=0,52).

3) O observador 2 apresentou a maior concordância com o padrão-ouro no pólo lateral $($ kappa=0,84) e a menor no pólo medial (Kappa=0,57).

Tabela 5.4 - Tabela das análises das imagens parassagitais: Kappa em relação ao padrão ouro

\begin{tabular}{l|c|c|c|c|c}
\hline Kappa & Medial & Lateral & Anterior & Posterior & Superior \\
\hline Obs1 & 0,37 & 0,75 & 0,66 & 0,53 & 0,79 \\
$\mathrm{p}$ & 0,004 & $<0,001$ & $<0,001$ & 0,001 & $<0,001$ \\
Obs1' & 0,64 & 0,73 & 0,77 & 0,81 & 0,90 \\
$\mathrm{p}$ & $<0,001$ & $<0,001$ & $<0,001$ & $<0,001$ & $<0,001$ \\
& & & & & \\
Obs2 & 0,79 & 0,84 & 0,85 & 0,63 & 0,67 \\
$\mathrm{p}$ & $<0,001$ & $<0,001$ & $<0,001$ & $<0,001$ & $<0,001$ \\
\hline
\end{tabular}

1) 0 observador 1 , na primeira medida, apresentou a maior concordância com o padrão-ouro no pólo superior (kappa=0,79) e a menor no pólo medial (kappa=0,37).

2) $O$ observador 1 , na segunda medida, apresentou a maior concordância com o padrão-ouro no pólo superior (kappa $=0,90)$ e a menor no pólo medial (kappa=0,64).

3) O observador 2 apresentou a maior concordância com o padrão-ouro no pólo anterior (kappa $=0,85)$ e a menor no pólo posterior (Kappa=0,63). 
O observador 1 apresentou maior concordância com o padrão-ouro no pólo superior nas imagens parassagitais, na primeira medida e na segunda.

O observador 2 apresentou maior concordância com o padrão-ouro no pólo anterior nas imagens parassagitais.

Os dois observadores apresentaram menor concordância com o padrão-ouro no pólo medial das imagens axiais, coronais e sagitais.

Nas imagens parassagitais o observador 1 apresentou menor concordância no medial e o observador 2 na posterior.

Tabela 5.5 - Tabela do estudo da porcentagem de concordância em cada pólo analisado

\begin{tabular}{l|c|c|c|c|c}
\hline \multicolumn{1}{c|}{ Tipo } & Medial & Lateral & Anterior & Posterior & Superior \\
\hline Axial, coronal & & & & & \\
e Sagital & $27(90,0 \%)$ & $29(96,7 \%)$ & $26(86,7 \%)$ & $24(80,0 \%)$ & $27(90,0 \%)$ \\
Parassagitais & $21(70,0 \%)$ & $29(96,7 \%)$ & $25(83,3 \%)$ & $24(80,0 \%)$ & $27(90,0 \%)$ \\
\hline $\mathrm{p}^{*}$ & 0,530 & - & 0,718 & - & - \\
\hline
\end{tabular}

$\left.{ }^{*}\right)$ nível descritivo do teste qui-quadrado

Portanto observamos pela tabela acima que os tipos de imagem não apresentam diferença significativa em relação às porcentagens de concordância nos pólos analisados.

Tabela 5.6 - Tabela de estudo do número de perfurações encontradas em cada pólo

\begin{tabular}{c|c|c|c|c|c}
\hline \multirow{2}{*}{$\begin{array}{c}\text { Total 30 } \\
\text { Côndilos }\end{array}$} & \multicolumn{5}{|c}{ Número de perfurações encontradas em cada pólo } \\
\cline { 2 - 6 } & Medial & Lateral & Anterior & Posterior & Superior \\
\hline Observador 1 & 17 & 22 & 19 & 24 & 24 \\
& $(56,6 \%)$ & $(73,3 \%)$ & $(63,3 \%)$ & $(80 \%)$ & $(80 \%)$ \\
Observador 1' & 24 & 25 & 21 & 24 & 23 \\
& $(80 \%)$ & $(83,3 \%)$ & $(70 \%)$ & $(80 \%)$ & $(76,6 \%)$ \\
Observador 2 & 23 & 22 & 19 & 22 & 26 \\
& $(76,6 \%)$ & $(73,3 \%)$ & $(63,3 \%)$ & $(73,3 \%)$ & $(86,6 \%)$ \\
Padrão Ouro & 25 & 22 & 21 & 23 & 23 \\
& $(83,3 \%)$ & $(73,3 \%)$ & $(70 \%)$ & $(76,6 \%)$ & $(76,6 \%)$ \\
\hline
\end{tabular}


Em relação à tabela de números de perfurações em cada pólo foi observada que a maior concordância foi no pólo lateral, apesar de mostrar um valor significativo em relação ao número de falsos positivos relacionados ao observador 1 '.

A menor concordância foi no pólo medial, mostrando valores significativamente baixos relacionados ao observador 1 e 2 sobre a taxa de falsos negativos. No pólo superior houve valores superiores no observador 1 e 2 sobre a taxa de falsos positivos.

Em relação aos valores nos pólos anteriores e posteriores houve valores não muito significativos relacionados observadores $X$ padrão ouro

Tabela 5.7 - Tabela do número de perfurações em relações às brocas e padrão ouro

\begin{tabular}{c|c|c|c|c|c}
\hline \multirow{2}{*}{$\begin{array}{c}\text { Total 30 } \\
\text { Côndilos }\end{array}$} & \multicolumn{5}{|c}{ Número de perfurações em relação às brocas e padrão ouro } \\
\cline { 2 - 6 } & Medial & Lateral & Anterior & Posterior & Superior \\
\hline Broca 1 & 10 & 8 & 7 & 6 & 7 \\
\hline Broca 3 & 7 & 7 & 7 & 9 & 8 \\
\hline Broca 6 & 8 & 7 & 7 & 8 & 8 \\
\hline Total & 25 & 22 & 21 & 23 & 23 \\
\hline
\end{tabular}

Em um total de 30 cabeças de mandíbulas avaliadas e relacionados aos 5 pólos foram encontrados, um total de 25 perfurações no pólo medial (broca 1=10; broca 3=7; broca 6=8), 22 perfurações no pólo lateral (broca 1=8; broca 3=7; broca 6=7), 21 perfurações no pólo anterior(broca $1=7$; broca $3=7$; broca $6=7$ ), 23 perfurações no pólo posterior(broca 1=6; broca 3=9; broca 6=8), 23 perfurações no pólo superior (broca 1=7; broca 3=8; broca 6=8). 
Tabela 5.8 - Tabela das porcentagens de falsos negativos, segundo a broca para cada observador

\begin{tabular}{l|c|c|c|c|c|c|c}
\hline \multirow{2}{*}{ Local } & \multirow{2}{*}{ Brocas } & \multicolumn{6}{|c}{ Observador } \\
\cline { 3 - 8 } & & \multicolumn{2}{|c|}{$\mathbf{1}$} & \multicolumn{2}{|c|}{$\mathbf{1}^{\prime}$} & \multicolumn{2}{|c}{$\mathbf{2}$} \\
\cline { 3 - 8 } & $\mathbf{n}$ & $\mathbf{\%}$ & $\mathbf{n}$ & $\mathbf{\%}$ & $\mathbf{n}$ & $\mathbf{\%}$ \\
\hline \multirow{2}{*}{ Axial, Coronal e Sagital } & Broca 1 & 11 & 91,7 & 6 & 85,7 & 11 & 78,6 \\
& Broca 3 & 1 & 8,3 & 1 & 14,3 & 3 & 21,4 \\
& Broca 6 & 0 & 0,0 & 0 & 0,0 & 0 & 0,0 \\
& Broca 1 & 5 & 83,3 & 5 & 83,3 & 6 & 75,0 \\
& Broca 3 & 0 & 0,0 & 0 & 0,0 & 2 & 25,0 \\
& Broca 6 & 1 & 16,7 & 1 & 16,7 & 0 & 0,0 \\
\hline
\end{tabular}

Observa-se que para todos os observadores a maior $\%$ de casos de falsos negativos esta na broca1, nos dois locais analisados.

Tabela 5.9 - Tabela dos valores de sensibilidade (\%)

\begin{tabular}{l|c|c|c|c|c|c}
\hline Estudo & Sensibilidade & Medial & Lateral & Anterior & Posterior & Superior \\
\hline Axial, Coronal & & & & & & \\
e Sagital & Obs1 & 68,0 & 90,9 & 66,7 & 87,0 & 91,3 \\
& Obs2 & 80,0 & 90,9 & 81,0 & 91,3 & 91,3 \\
& & & & & & \\
Parassagitais & Obs1 & 64,0 & 90,9 & 76,2 & 78,3 & 100,0 \\
& Obs2 & 92,0 & 90,9 & 90,5 & 91,3 & 100,0 \\
\hline
\end{tabular}

Observamos que os maiores valores de sensibilidade foram encontrados nos pólos superiores, para os dois observadores nos dois métodos.

Tabela 5.10 -Tabela dos valores de especificidade (\%)

\begin{tabular}{l|l|c|c|c|c|c}
\hline Estudo & Especificidade & Medial & Lateral & Anterior & Posterior & Superior \\
\hline Axial, Coronal & & & & & & \\
e Sagital & Obs1 & 100,0 & 87,5 & 88,9 & 71,4 & 71,4 \\
& Obs2 & 100,0 & 100,0 & 100,0 & 85,7 & 85,7 \\
& & & & & & \\
Parassagitais & Obs1 & 100,0 & 87,5 & 100,0 & 85,7 & 71,4 \\
& Obs2 & 100,0 & 100,0 & 100,0 & 71,4 & 57,1 \\
\hline
\end{tabular}

Observamos que os maiores valores de especificidade foram encontrados nos pólos medial, lateral e anterior, para os dois observadores nos dois métodos. 


\section{DISCUSSÃO}

A tomografia computadorizada (TC) multislice representa um grande avanço na TC, pois permite obter cortes mais finos e com alta resolução de reconstrução das imagens em menos de um segundo de tempo de aquisição.

Estudos recentes demonstraram que a TC é um grande adjunto para exames de anormalidades da cavidade oral e estruturas adjacentes, já que proporciona a visualização de estruturas de tecido mole e duro no mesmo exame, tendo como vantagem sua execução sem sobreposição de imagens, inclusive em áreas como a região da ATM. TC é uma das técnicas mais modernas que temos atualmente no que se refere à visualização de patologias maxilo-faciais, auxiliando no seu diagnóstico e planejamento de tratamento.

Ludlow, Davies e Tyndall (1995) realizaram um estudo comparativo in vitro de diagnóstico de acurácia para detecção de alterações ósseas na região de ATM pela tomografia multislice utilizando imagens sagital, coronal (reconstrução multiplanares) e radiografias panorâmicas. Foram inseridas microplacas em quatro posições na cabeça da mandíbula no crânio humano seco, onde foram realizadas tomografias e radiografias panorâmicas. Os números iguais de imagens com ou sem as microplacas foram marcados por quatro examinadores com o uso de níveis de confiança para a presença ou a ausência da lesão. As respostas foram avaliadas gerando curvas de características do funcionamento de receptor e analisando a área sob curvas com análise de métodos de variação. As reconstruções multiplanares forneceram mais acurácia na avaliação de lesões na cabeça da mandíbula que imagens panorâmicas biplanares $(p=0.007)$. Nenhuma diferença estatística pela 
posição $(p=0.592)$ foi encontrada. Os resultados do observador e observação repetida eram valores significativos no $p=0.046$ e no $p=0.030$, respectivamente. Esses valores tiveram influências estatisticamente consideráveis no que se refere às distorções encontradas nas imagens panorâmicas. Em comparação ao estudo de Ludlow, Davies e Tyndall (1995), o presente estudo demonstrou diferenças estatísticas em relação a posição das lesões simuladas na cabeça da mandíbula, isto influenciadas ao diâmetro das brocas e a quantidade das perfurações em cada pólo. Em relação à concordância em cada pólo analisado, verificou-se que os tipos de imagem não apresentaram diferenças muito significativas em relação às porcentagens de concordância nos pólos analisados. Nos pólos laterais, posterior e superior, os valores de $p^{*}$ do teste qui-quadrado foi valor $p^{*}=1$, sendo que nos pólos medial e anterior, respectivamente, $\mathrm{P}^{*}=0,530$ e $\mathrm{P}^{*}=0,718$.

No estudo de Warnke, Carls e Sailer (1996) para aplicabilidade de um programa de reconstrução multiplanar (DENTASCAN) para delineamento e avaliação quantitativa da articulação temporomandibular em plano sagital e coronal, usando dados de tomografia computadorizada axial, tiveram resultados de $100 \%$ na visualização de alterações ósseas patológicas. Utilizando um programa onde facilmente é possível ser instalado em uma plataforma de um computador pessoal, pode-se reconstruir imagens originais em cortes parassagitais provenientes de qualquer fonte com imagens DICOM (Digital Imaging Communication in Medicine), podendo contribuir para detecção de lesões na cabeça da mandíbula de acordo com a sua localização anatômica.

Em relação à pesquisa de Perrella et al. (2007), a sensibilidade e a especificidade foram de $100 \%$ para detecção de lesões simuladas no corpo da mandíbula para ambos os protocolos (singleslice e multislice). Entretanto, a 
detecção do número de lojas das lesões multiloculares e a localização e detecção de invasão medular obtiveram valores reduzidos em sua validade, o que foi influenciado pelo protocolo de aquisição. Os cortes axiais e intervalos de reconstruções mais finos foram responsáveis por resultados mais efetivos na detecção de invasão medular precoce e numero e localização das lojas. Os protocolos mais espessos não foram considerados apropriados para a detecção de lesões multiloculares e estágios iniciais de invasão medular. Em diferença do estudo de Perrella et al. (2007) para o presente estudo, os valores tiveram ligeiras reduções de valores referentes a cada pólo determinado, apresentando valores de delineamento da lesão. Com isto a avaliação da sua localização exata, o resultado referente à sensibilidade, foi para axial, coronal e sagital: medial (68\%), lateral $(90,9 \%)$, anterior $(66,7 \%)$, posterior $(87 \%)$, superior $(91,3 \%)$ em relação ao observador 1 ; medial $(80 \%)$, lateral $(90,9 \%)$, anterior $(81 \%)$, posterior $(91,3 \%)$, superior $(91,3 \%)$ em relação ao observador 2. Em relação aos cortes parassagitais obtivemos os seguintes valores de sensibilidade para cada pólo: medial $(64 \%)$, lateral $(90,9 \%)$, anterior $(76,2 \%)$, posterior $(78,3 \%)$, superior $(100 \%)$ em relação ao observador 1 ; medial $(92 \%)$, lateral $(90,9 \%)$, anterior $(90,5 \%)$, posterior $(91,3 \%)$, superior $(100 \%)$ em relação ao observador 2. Observamos que os maiores valores de sensibilidade foram encontrados nos pólos superiores, para os dois métodos, visto a facilidade de visualização do pólo superior nas imagens realizadas. Os valores reduzidos não foram influenciados pelo protocolo de aquisição e sim pelo tamanho da broca 1, que foi dificultada em sua avaliação para os diferentes pólos.

Koyama, Nishiyama e Hayashi (2007) realizaram um estudo no qual sugeriram uma classificação das imagens em reconstruções multiplanares (RMP) do TC helicoidal em 5 tipos: $\mathrm{N}$ - no bone change (sem alteração óssea); F - flattening 
(aplainado); E - erosion with or without roughening (erosão com ou sem superfície áspera); D - deformity (deformidade); S - deformity accompanied by erosion with or without roughening (deformidade acompanhada de erosão com ou sem superfície áspera). Nos resultados, foram observados em 617 (63,7\%) alterações ósseas condilares de 1032 ATM, e o número de articulações para cada tipo de alterações ósseas condilares foram: Tipo F 83 (8\%), Tipo E 197 (19\%), Tipo D 197 (19\%), Tipo S 147 (14\%). Dos 51 casos acompanhados de 102 articulações, alterações ósseas condilares foram vistas em $70(69 \%)$ das 102 articulações sendo: Tipo F 12 (12\%), Tipo E 14 (14\%), Tipo D 20 (20\%), Tipo S 24 (24\%). Realizaram comparações entre as imagens de TC iniciais e as secundárias no acompanhamento resultando em aumento dos tipos $\mathrm{E}$ e $\mathrm{D}$, mas diminuição dos tipos $\mathrm{N}, \mathrm{F}$ e $\mathrm{S}$. Na presente pesquisa foram realizadas perfurações simuladas esféricas que simulou uma possível lesão óssea, mas que não foram classificadas devido a sistematização das perfurações com as diferentes brocas de tamanhos de ponta ativa diferentes.

Kijima et al. (2007) realizaram um estudo utilizando tomografia computadorizada, referente a relação da morfologia da cabeça da mandíbula e a espessura do teto da fossa glenóide. No estudo verificou-se que a espessura da fossa glenóide na comparação com pacientes do gênero masculino e feminino não teve diferenças significativas. Além disso, não foram encontradas, segundo os autores, diferenças significativas referentes às conseqüências da variação na idade ou na morfologia principal mandibular.

Para melhor visualização das imagens, as mandíbulas foram mergulhadas em recipientes contendo água para simulação das estruturas de tecidos moles. Das diversas alterações ósseas que a cabeça da mandíbula possui, foram realizadas lesões ósseas simuladas com caneta de alta rotação, com o uso de brocas esféricas 
de tamanhos diferentes. Com o intuito de facilitar a análise de cada pólo da cabeça da mandíbula perfurada, foram classificadas segundo cada localização: 1- pólo anterior, 2- pólo lateral, 3- pólo posterior, 4- pólo medial, 5- pólo superior. Nenhuma classificação referente à visualização de cada pólo foi encontrada na literatura.

No trabalho de Cara et al. (2007) foram avaliadas e comparadas a validades de diferentes protocolos single e multislice para análises de lesões simuladas na cabeça da mandíbula. No resultados de validade apresentada em cada protocolo foram: protocolo 1 single slice-axial $(62,7 \%)$, protocolo 2 multislice-axial $(66,2 \%)$, protocolo 3 single slice-axial/reconstruções multiplanares $(72,7 \%)$, protocolo 4 multislice-axial/reconstruções multiplanares $(93,1 \%)$. Com a associação das imagens axiais com reconstruções multiplanares (RMP), utilizando tomografia computadorizada multislice, foi demonstrada alta acurácia em relação ao protocolo single slice. Em continuidade a esse estudo, o presente trabalho determinou a validade das imagens obtidas pela tomografia computadorizada multislice por meio de protocolos diferentes em reconstruções multiplanares e utilização de cortes parassagitais. Nos resultados apresentados, foi demonstrado que, para cada pólo específico, houve facilidade e dificuldade na visualização das lesões simuladas por cada protocolo de reconstrução multiplanar e pelos cortes parassagitais, apresentados pelos observadores. Para análise intra e inter-examinadoras, foram demonstrados pelo teste estatístico de Kappa. Em análise do Kappa intraobservador, o menor valor encontrado se encontra no pólo medial $(0,38)$ dos cortes parassagitais, e o maior, no pólo posterior $(0,91)$ das axiais, coronais e sagitais. Os valores encontrados nos pólos medial $(0,42)$ e posterior $(0,91)$ nos cortes axiais, coronais e sagitais foram maiores que os encontrados nos cortes parasagitais, pólo medial $(0,38)$ e posterior $(0,53)$. Nos pólos lateral $(0,66)$, anterior $(0,59)$ e superior 
$(0,67)$, foram valores maiores encontrados em comparação com os valores dos cortes axiais, coronais e sagitais, pólo lateral $(0,56)$, pólo anterior $(0,53)$ e superior $(0,51)$

$\mathrm{Na}$ análise inter-observadores (primeiras e segundas análises respectivamente) foi observada um valor de Kappa maior nas imagens parassagitais no pólo posterior $(0,53$ e 0,81$)$ em relação a $(0,49$ e 0,56$)$ na axial, coronal e sagital, considerando os dois valores. Nos pólos medial $(0,79$ e 0,40), lateral $(0,92$ e 0,67), anterior $(0,73$ e 0,79$)$ e superior $(0,73$ e 0,63$)$, foram os valores encontrados nos cortes parassagitais; nos pólos medial $(0,38$ e 0,49), lateral $(0,92$ e 0,60$)$, anterior $(0,66$ e 0,93$)$ e superior $(0,61$ e 0,76$)$, foram os valores encontrados em relação aos cortes axial, coronal e sagital. Na primeira medida do observador 1, somente no pólo posterior verificou-se um Kappa maior nas imagens parassagitais em relação a axial, coronal e sagital. Na segunda medida do observador 1, no pólo lateral foi verificado maior valor no corte axial, coronal e sagital que nos cortes parassagitais.

Nos resultados do Kappa em relação ao padrão ouro no estudo dos cortes axial, coronal e sagital, verificou-se que o observador 1, na primeira medida, apresentou a maior concordância com o padrão-ouro no pólo lateral $(0,75)$, e a menor, no pólo medial $(0,42)$. O observador 1 , na segunda medida, apresentou a maior concordância com o padrão-ouro no pólo superior $(0,90)$, e a menor, no pólo medial $(0,52)$. O observador 2 apresentou a maior concordância com o padrão-ouro no pólo lateral $(0,84)$, e a menor, no pólo medial $(0,57)$.

Em relação aos estudos das imagens parassagitais, verificou-se que, o observador 1, na primeira medida, apresentou a maior concordância com o padrãoouro no pólo superior $(0,79)$, e a menor, no pólo medial $(0,37)$. O observador 1 , na segunda medida, apresentou a maior concordância com o padrão-ouro no pólo 
superior $(0,90)$, e a menor, no pólo medial $(0,64)$. Em relação ao observador 2 , foi apresentada a maior concordância com o padrão-ouro no pólo anterior $(0,85)$, e a menor, no pólo posterior $(0,63)$.

O observador 1 apresentou maior concordância com o padrão-ouro no pólo superior nas imagens parassagitais, na primeira medida e na segunda. $O$ observador 2 apresentou maior concordância com o padrão-ouro no pólo anterior nas imagens parassagitais. Os dois observadores apresentaram menor concordância com o padrão-ouro no pólo medial das axiais. Nas imagens parassagitais, o observador 1 apresentou menor concordância no pólo medial, e o observador 2, no pólo posterior.

Em relação às brocas selecionadas no estudo de tamanho 1, 3 e 6 os observadores tiveram maiores valores de falso negativos na broca 1: nos cortes axial, coronal e sagital, observador $1(91,7 \%)$, observador 1' $(85 \%)$, observador 2 . Nos cortes parassagitais, observador $1(83,3 \%)$, observador 1' $(75, \%)$, observador 2 . Demonstrou-se no estudo a dificuldade de visualização nos dois protocolos de pequenas lesões realizadas pela broca 1.

Em relação à capacidade de detectar a presença da lesão, isto é, o valor da sensibilidade (falso negativo), os dois observadores apresentaram maiores valores no pólo superior nos dois referidos protocolos. Na capacidade de detectar ausência de lesão (valor de especificidade), foi observado que os maiores valores de especificidade foram encontrados nos pólos medial, lateral e anterior. No resultado do nosso estudo de especificidade, foram nos axial, coronal e sagital para cada pólo: medial $(100 \%)$, lateral $(87,5 \%)$, anterior $(88,9 \%)$, posterior $(71,4 \%)$, superior $(71,5 \%)$ em relação ao observador 1 ; medial (100\%), lateral $(100 \%)$, anterior $(100 \%)$, posterior $(85,7 \%)$, superior $(85,7 \%)$ em relação ao observador 2 . Nos estudos dos 
cortes parassagitais para cada pólo: medial (100\%), lateral $(87,5 \%)$, anterior $(100 \%)$, posterior $(85,7 \%)$, superior $(71,4 \%)$ em relação ao observador 1 ; medial $(100 \%)$, lateral $(100 \%)$, anterior $(100 \%)$, posterior $(71,4 \%)$, superior $(57,1 \%)$ em relação ao observador 2 .

Quanto aos pólos avaliados de acordo com os resultados do protocolo de cortes parassagitais, houve melhor visualização nos pólos anterior e posterior nas imagens do corte parassagital no sentido látero-medial. Nos pólos superior, medial e lateral, foram mais bem visualizados no sentido ântero-posterior.

Um grande adjunto de protocolos para visualização da região da cabeça da mandíbula foi estabelecido no intuito de melhorar a visualização da presença de alterações de cada pólo da cabeça da mandíbula. 


\section{CONCLUSÕES}

Foi estabelecida a validade da TC multislice na detecção de lesões da cabeça de mandíbula em ambos os protocolos:

- Os protocolos para visualização da região da cabeça da mandíbula foram estabelecidos no intuito de melhorar a visualização da presença de alterações de cada pólo da cabeça da mandíbula.

- No que se refere aos pólos avaliados pelos cortes parassagitais houve melhor visualização no pólo anterior e posterior no sentido látero medial. Nos pólos superior, medial e lateral foram mais bem visualizados no sentido ântero-posterior.

- Houve maior dificuldade na avaliação de lesões simuladas de pequena dimensão (broca 1).

- Ambos os protocolos em conjunto auxiliaram no complemento do diagnóstico da lesão simulada na cabeça da mandíbula. 


\section{REFERÊNCIAS ${ }^{1}$}

Abrahams JJ. Dental CT imaging: a look at the jaw. Radiology 2001;219:334-45.

Ahlqvist JB, Isberg AM. Validity of computed tomography in imaging thin walls of the temporal bone. Dentomaxillofac Radiol 1999;28(1):13-9.

Bóscolo F; Almeida SM; Paganini GA. Estudo da imagem da ATM por duas técnicas radiográficas. RGO 1998;46(4):222-9.

Cara AC, Gaia BF, Perrella A, Oliveira JX, Lopes PM, Cavalcanti MG. Validity of single- and multislice CT for assessment of mandibular condyle lesions.

Dentomaxillofac Radiol 2007;36(1):24-7.

Cavalcanti MG, Vannier MW. Quantitative analysis of spiral computed tomography for craniofacial clinical applications. Dentomaxillofac Radiol 1998;27(6):344-50.

Cavalcanti MG. Diagnóstico por imagem da face. $1^{\circ}$ ed. São Paulo: Editora Santos; 2008.

Christiansen EL, Chan TT, Thompson JR, Hasso AN, Hinshaw DB Jr, Kopp S. Computed tomography of the normal temporomandibular joint. Scand J Dent Res 1987a; 95: 499-509.

Christiansen EL, Thompson JR, Zimmerman G, Roberts D, Hasso AN, Hinshaw DB JR, Kopp S. Computed tomography of condylar and articular disk positions within the temporomandibular joint. Oral Surg Oral Med Oral Pathol.1987b;64(6):757-67.

De bont LG, Van Der Kuijl B, Stegenga B, Vencken LM, Boering G. Computed tomography in differential diagnosis of temporomandibular joint disorders. Int J Oral Maxillofac Surg 1993;22(4):200-9.

El-hakim IE, Metwalli SA. Imaging of temporomandibular joint ankylosis. A new radiographic classification. Dentomaxillofacial Radiol 2002;31(1):19-23.

\footnotetext{
${ }^{1}$ De acordo com Estilo Vancouver. Abreviatura de periódicos segundo base de dados MEDLINE.
} 
Gaia BF, Cavalcanti MGP. Afecções ósseas da articulação temporomandibular: protocolos em tomografia computadorizada. Rev Assoc Paul Cir Dent 2005:59 (4):297-302.

Greess $\mathrm{H}$, Anders K. Indications for validity of computed tomography and magnetic resonance imaging of the temporomandibular joint] .Rontgenpraxis 2005;56(1):1-11.

Gynther GW, Tronje G, Holmlund AB. Radiographic changes in the temporomandibular joint in patients with generalized osteoarthritis and rheumatoid arthritis. Oral Surg Oral Med Oral Pathol Oral Radiol Endod 1996 May;81(5):613-8.

Helms CA, Morrish RB Jr, Kircos LT, Katzberg RW, Dolwick MF. Computed tomography of the Meniscus of the temporomandibular joint: preliminary observations. Radiology 1982;145:719-22.

Hernandez, R. Estudo comparativo das imagens obtidas pela reconstrução volumétrica, por meio da tomografia computadorizada helicoidal, e pela ressonância magnética, das estruturas ósseas da articulação temporomandibular, em pacientes portadores da disfunção da articulação temporomandibular sem comprometimento ósseo [Tese Doutorado] São Paulo: Faculdade de Odontologia, USP; 1999.

Hintze $\mathrm{H}$, Wiese M, Wenzel A. Cone beam CT and conventional tomography for the detection of morphological temporomandibular joint changes. Dentomaxillofac Radiol 2007;36(4):192-7.

Honda K, Larheim TA, Maruhashi K, Matsumoto K, Iwai K. Osseous abnormalities of the mandibular condyle: diagnostic reliability of cone beam computed tomography compared with helical computed tomography based on anautopsy material. Dentomaxillofac Radiol 2006;35(3):152-7.

Hussain AM, Packota G, Major PW, Flores-Mir C. Role of different imaging modalities in assessment of temporomandibular joint erosions and osteophytes: a systematic review. Dentomaxillofac Radiol 2008;37(2):63-71.

Jäger L, Bonell H, Liebl M, Srivastav S, Arbusow V, Hempel M, Reiser M. CT of the normal temporal bone: comparison of multi- and single-detector row CT. Radiology $2005 ; 235(1): 133-41$.

Kijima N, Honda K, Kuroki Y, Sakabe J, Ejima K, Nakajima I. Relationship between patient characteristics, mandibular head morphology and thickness of the roof of the 
glenoid fossa in symptomatic temporomandibular joints. Dentomaxillofac Radiol 2007;36(5):277-81.

Kirk WS Jr. A comparative study of axial corrected tomography with magnetic resonance imagery in 35 joints. Oral Surg Oral Med Oral Pathol 1989;68(5):646-52.

Koyama J, Nishiyama H, Hayashi T. Follow-up study of condylar bony changes using helical computed tomography in patients with temporomandibular disorder.Dentomaxillofac Radiol 2007;36(8):472-7.

Larhein TA, Johannessen S. Transpharyngeal radiography of mandibular condyle: comparison with other conventional methods. Acta Radiol Diagn1985;26(2):167-71.

Ludlow JB, Davies KL, Tyndall DA. Temporomandibular joint imaging: a comparative study of diagnostic accuracy for the detection of bone change with biplanar multidirectional tomography and panoramic images. Oral Surg Oral Med Oral Pathol Oral Radiol Endod 1995;80(6):735-43.

Manzione JV, Katzberg RW, Brodsky GL, Seltzer SE, Mellins HZ. Internal derangements of the temporomandibular joint: diagnosis by direct sagittal computed tomography. Radiology 1984;150(1):111-5.

Marques, A.P. Prevalência de alterações da articulação temporomandibular por meio de exames de tomografia computadorizada [Dissertação mestrado]. São José dos Campos: Faculdade de Odontologia da UNESP; 2001.

Moaddab MB, Dumas AL, Chavoor AG, Neff PA, Homayoun N. Temporomandibular joint: computed tomographic three-dimensional reconstruction. Am J Orthod 1985 Oct;88(4):342-52.

Perrella A, Borsatti MA, Tortamano IP, Rocha RG, Cavalcanti MG. Validation of computed tomography protocols for simulated mandibular lesions: a comparison study. Braz Oral Res 2007;21(2):165-9.

Perrella A. Avaliação da eficácia dos protocolos de tomografia computadorizada na identificação de lesões na mandíbula com interferência de artefatos metálicos dentários [Tese Mestrado] São Paulo: Faculdade de Odontologia da USP; 2006. 
Sales MA, Oliveira JX, Cavalcanti MG. Computed tomography imaging findings of simultaneous bifid mandibular condyle and temporomandibular joint ankylosis: case report. Braz Dent J 2007;18(1):74-7.

Santos DT, Cavalcanti MGP. Osteossarcoma of the temporomandibular joint. Report of two cases. Oral Surg Oral Med Oral Pathol Oral Radiol Endod 2002;94:641-7.

Tanimoto K, Petersson A, Rohlin M, Hansson LG, Johansen CC. Comparison of computed with conventional tomography in the evaluation of temporomandibular joint disease: a study of autopsy specimens. Dentomaxillof Radiol 1990;19:21-7.

Thompson JR, Christiansen E, Hasso AN, Hinshaw DB JR. Temporomandibular joints: high-resolution computed tomographic evaluation. Radiology 1984;150(1):105-10.

Tsiklakis K, Syriopoulos K, Stamatakis HC. Radiographic examination of the temporomandibular joint using cone beam computed tomography. Dentomaxillofac Radiol 2004;33(3):196-201.

Tsuruta A, Yamada K, Hanada K, Hosogai A, Tanaka R, Koyama J, Hayashi T. Thickness of the roof of the glenoid fossa and condylar bone change: a CT study. Dentomaxillofacial Radiol 2003;32(4):217-21.

Utumi ER, Sales MAO, Shinohara EH, Takahashi A, Coracin FL, Rocha RG, et al. SAPHO syndrome with temporomandibular joint ankylosis: clinical, radiological,histopathological, and therapeutical correlations. Oral Surg Oral Med Oral Pathol Oral Radiol Endod 2008;105(3):e67-72.

Van den Brekel MW, Runne RW, Smeele LE, Tiwari RM, Snow GB, Castelijns JA. Assessment of tumor invasion into the mandible: the value of different imaging techniques. Eur Radiol 1998;8:1552-7.

Vannier MW. Craniofacial computed tomography scanning: technology, applications and future trends. Orthod Craniofac Res 2003;6:23-30; discussion 179-82.

Warnke T, Carls FR, Sailer HF. A new method for assessing the temporomandibular joint quantitatively by dental scan. J Craniomaxillofac Surg 1996;24(3):168-72. 
Westesson PL, Katzberg RW, Tallents RH, Sanchez-Woodworth RE, Svensson SA, Espeland MA. CT and MR of the temporomandibular joint: comparison with autopsy specimens. Am J Roentg1987:148:1165-71.

Westesson PL. Temporomandibular joint and dental imaging. Neuroimaging Clin North Am1996;6(2):333-55.

Yamada K, Tsuruta,A, Hanada K, Hayashi,T. Morphology of the articular eminence in temporomandibular joints and condylar bone change. JOral Rehabil 2004;31(5):438-44. 
ANEXO A - Parecer do Comitê de Ética em Pesquisa

\title{
UNIVERSIDADE DE SÃO PAULO FACULDADE DE ODONTOLOGIA
}

\author{
PARECER DE APROVAÇÃO \\ Protocolo 141/07
}

O grupo de trabalho indicado pelo Comitê de Ética em Pesquisa APROVOU o protocolo de pesquisa "AVALIAÇÃo DE LESÕES ÓSSEAS NA CABEÇA DA MANDÍBULA PELA TOMOGRAFIA COMPUTADORIZADA", de responsabilidade do Pesquisador: ESTEVAM RUBENS UTUMI, sob orientação do Professor Doutor MARCELO DE GUSMÃO PARAISO CAVALCANTI.

Tendo em vista a legislação vigente, devem ser encaminhados a este Comitê relatórios anuais referentes ao andamento da pesquisa e ao término cópia do trabalho em "cd". Qualquer emenda do projeto original deve ser apresentada a este CEP para apreciação, de forma clara e sucinta, identificando a parte do protocolo a ser modificada e suas justificativas.

São Paulo, 04 de outubro de 2007

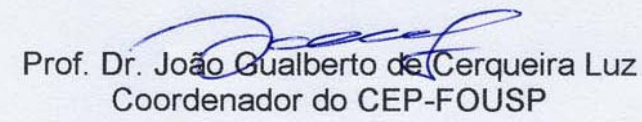

Av. Prof. Lineu Prestes, 2227 - Cidade Universitária "Armando de Salles Oliveira" CEP 05508-900 São Paulo - SP - Diretoria Telefax: (011) 3091- 0062/3091-7817/3091-7860 - Compras (011) 3091-7895 Impresso no S.D.O. 